\title{
Resolution of impact-related microstructures in lunar zircon: A shock-deformation mechanism map
}

\author{
Nicholas E. TIMMS ${ }^{*}$, Steven M. REDDY ${ }^{1}$, David HEALY ${ }^{2}$, Alexander A. NEMCHIN ${ }^{1}$, \\ Marion L. GRANGE ${ }^{1}$, Robert T. PIDGEON ${ }^{1}$, and Robert HART ${ }^{3}$ \\ ${ }^{1}$ Department of Applied Geology, Curtin University, G.P.O. Box U1987, Perth, Western Australia 6845, Australia \\ ${ }^{2}$ School of Geosciences, King's College, University of Aberdeen, Aberdeen AB24 3UE, UK \\ ${ }^{3}$ Centre for Materials Research, Curtin University, G.P.O. Box U1987, Perth, Western Australia 6845, Australia \\ *Corresponding author. E-mail: n.timms@curtin.edu.au
}

(Received 03 June 2011; revision accepted 10 November 2011)

\begin{abstract}
The microstructures of lunar zircon grains from breccia samples 72215, 73215, 73235, and 76295 collected during the Apollo 17 mission have been characterized via optical microscopy, cathodoluminescence imaging, and electron backscatter diffraction mapping. These zircon grains preserve deformation microstructures that show a wide range in style and complexity. Planar deformation features (PDFs) are documented in lunar zircon for the first time, and occur along $\{001\},\{110\}$, and $\{112\}$, typically with $0.1-25 \mu \mathrm{m}$ spacing. The widest PDFs associated with $\{112\}$ contain microtwin lamellae with $65^{\circ} \%<110>$ misorientation relationships. Deformation bands parallel to $\{100\}$ planes and irregular low-angle $\left(<10^{\circ}\right)$ boundaries most commonly have $<001\rangle$ misorientation axes. This geometry is consistent with a dislocation glide system with $<100>\{010\}$ during dislocation creep. Nonplanar fractures, recrystallized domains with sharp, irregular interfaces, and localized annealing textures along fractures are also observed. No occurrences of reidite were detected. Shockdeformation microstructures in zircon are explained in terms of elastic anisotropy of zircon. PDFs form along a limited number of specific $\{h k l\}$ planes that are perpendicular to directions of high Young's modulus, suggesting that PDFs are likely to be planes of longitudinal lattice damage. Twinned $\{112\}$ PDFs also contain directions of high shear modulus. A conceptual model is proposed for the development of different deformation microstructures during an impact event. This "shock-deformation mechanism map" is used to explain the relative timing, conditions, and complexity relationships between impactrelated deformation microstructures in zircon.
\end{abstract}

\section{INTRODUCTION}

The Earth and Moon preserve records of impact events throughout geological time (Stöffler and Ryder 2001). Large impact events on Earth can have a dramatic and rapid effect on the global climate, and have been linked to the $\mathrm{K}-\mathrm{T}$ mass extinction event. However, the temporal correlation between potential cause and effect depends on the acquisition of precise and accurate dates for impact and mass extinction events (Jourdan et al. 2009). During impact events, strong stress (elastic, elasticplastic, and shock) waves propagate through the target rocks (Melosh 1989). Shock waves travel at supersonic speeds away from the impact site with pressures that exceed the Hugoniot Elastic Limit $\left(\sigma_{\mathrm{HEL}}\right)$. Shock waves cause plastic damage at the abrupt wave fronts, and decay rapidly to elastic waves with distance (Melosh 1989). This is closely followed by excavation of a transient crater and a wake of incipient melting, vaporization, and ejection of debris, which happen in the order of a few minutes, depending on the scale of impact. Late stage crater modification occurs by gravity-driven slumping and creep (Melosh 1989). The types and distribution of features produced during crater formation can be attributed to shock conditions during impact events (Robertson and Grieve 1977; Grieve et al. 1996; Wittmann et al. 2006). 
$\mathrm{U}-\mathrm{Pb}$ dating of zircon $\left(\mathrm{ZrSiO}_{4}\right)$ can be the most accurate and precise way to date impact events (Krogh et al. 1984, 1993; Deutsch and Schärer 1994; Jourdan et al. 2009; Liu et al. 2009, 2010; Kelley and Sherlock, Forthcoming). The most reliable way to constrain an impact event is to date zircon crystallized during an impact event, either as neoblasts from impact melts (Krogh et al. 1984; Grange et al. 2009; Liu et al. 2009, 2010; Moser et al. 2011) or infilling fractures within older grains. Impact events also cause deformation in zircon contained in the target rocks and cause resetting of the $\mathrm{U}-\mathrm{Pb}$ system of zircon (Deutsch and Schärer 1990; Schärer and Deutsch 1990). The strained target rocks in the vicinity of impacts are much more voluminous than localized domains of crystallized impact melt. Consequently, impact-affected pre-existing grains are much more numerous and widespread than neoblasts, and have better potential to preserve evidence of impacts in the rock record, either in situ, or as eroded detritus (Cavosie et al. 2010).

\section{Shock Microstructures in Zircon and Phase Transformations}

Zircon from terrestrial impact sites can preserve a variety of impact-related microstructures. Nonplanar fractures (NPFs; Fig. 1A) and crystallographically controlled planar fractures (PFs; Fig. 1B) have been reported in zircon from impact sites on Earth and shockdeformation experiments. PFs are a type of closely spaced cleavage that can be indicative of shock conditions, particularly in minerals that do not form cleavage under most "tectonic" stress conditions, such as quartz (Langenhorst 2002). In this sense, PFs are true open fractures, and newly grown minerals and/or melt can occupy dilated fractures at the highest shock conditions (e.g., Moser et al. 2011). However, NPFs are not exclusively formed by impact shock, and could be formed by other processes (Leroux et al. 1999; Austrheim and Corfu 2009; Cavosie et al. 2010). For example, many lunar zircons preserve radial, and subparallel sets of NPFs (e.g., Nemchin et al. 2009). Textural relationships with surrounding material indicate that the formation of radial fractures is a result of radiation damage after the incorporation of the zircon clasts into the breccias (Meyer et al. 1996), indicating that this class of NPFs are not shock-related.

Several types of microstructure form unequivocal evidence of impacts. Planar deformation features (PDFs; Fig. 1G) are essentially thin $(<200 \mathrm{~nm})$ lamellae containing an amorphous phase, with the same composition as the host crystal, that occur along a limited number of rational, low index crystallographic planes in minerals (Grieve and Robertson 1976; Stöffler and
Langenhorst 1994; Langenhorst 2002). In PDFs in quartz at shock conditions below the melting temperature, the amorphous phase is a diaplectic glass that retains shortrange order (Stöffler and Langenhorst 1994). In PDFs formed above the melting temperature, quartz in PDFs forms a liquid that quenches to glass with flow textures (Lechatelierite) on the reduction of shock pressure (Stöffler and Langenhorst 1994). Vesicles and fluid inclusions associated with quenching of this phase can sometimes "decorate" PDFs (French 1969; Stöffler and Langenhorst 1994; Langenhorst 2002). Specific orientations of PDF planes in quartz are indicative of grades of shock metamorphism (Robertson and Grieve 1977; Langenhorst 2002). However, amorphous PDF formation is a function of textural and mineralogical environment. For example, particular $\{h k l\}$ PDF formation in quartz can vary by up to $4 \mathrm{GPa}$ in different rock types (Grieve and Robertson 1976; Langenhorst and Deutsch 1994). Consequently, studies of amorphous PDFs in natural shocked grains give only a broad estimate of maximum shock pressure conditions (Robertson and Grieve 1977; Stöffler and Langenhorst 1994). PDFs have generally been observed in zircon grains via optical microscopy, secondary electron (SE) imaging after weak etching with $\mathrm{NaOH}$, and transmission electron microscopy (TEM) (Leroux et al. 1999). In zircon, amorphous PDFs form along $\{320\}$ and $\{110\}$ at 40 and $60 \mathrm{GPa}$, respectively (Leroux et al. 1999).

Microtwin lamellae, such as Brazil twins in shocked quartz, can form during impact shock events and were previously regarded as PDFs because they are indistinguishable via optical microscopy (Langenhorst 2002). Analysis via TEM has confirmed impact-related mechanical microtwins in zircon that form lamellae along $\{112\}$ planes (Fig. 1H) (Leroux et al. 1999). Microtwins in zircon have a $65^{\circ}$ rotational symmetry around $\langle 110\rangle$, and can form at relatively low shock conditions $(<20 \mathrm{GPa}$, using quartz shock microstructures as a reference) (Moser et al. 2011). Dislocation creep microstructures (e.g., Figs. 1D-F) from a lower crustal xenolith near the Vredefort impact structure have been identified in zircon via electron backscatter diffraction (EBSD) mapping (Moser et al. 2009, 2011). These authors attribute the crystal-plastic deformation in the zircon to ductile flow in the lower crust during postimpact recovery. The oldest known lunar zircon (72215,195 zircon 1) preserves crystal-plastic deformation microstructures (Nemchin et al. 2009). In this grain, two sets of deformation bands lie parallel to $\{100\}$ planes and crosscut sector growth zoning. Impactrelated dislocation glide systems in zircon consistently have a $<100>\{010\}$ geometry (Leroux et al. 1999; Reimold et al. 2002; Moser et al. 2009; Nemchin et al. 2009). 
A

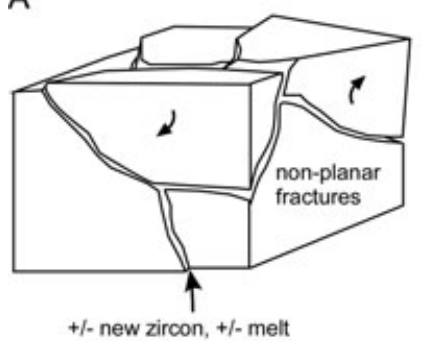

D

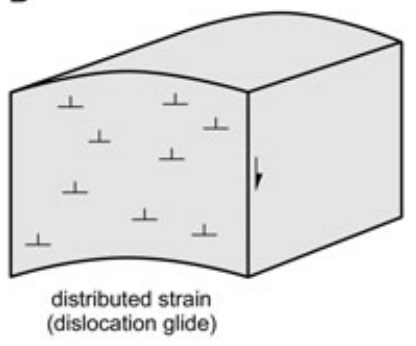

B

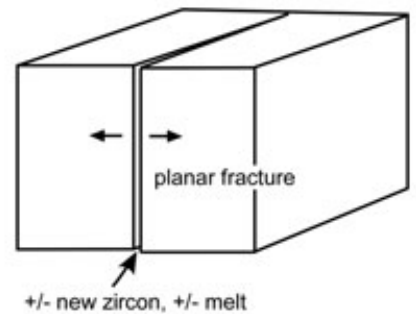

E
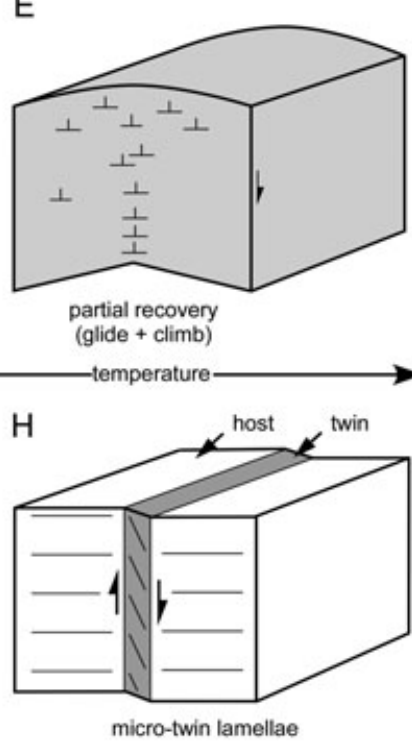

micro-twin lamellae
C

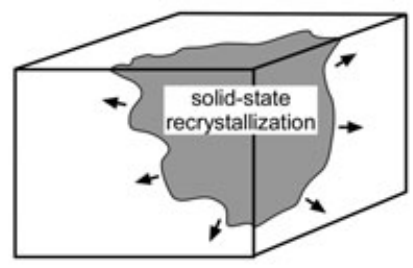

F

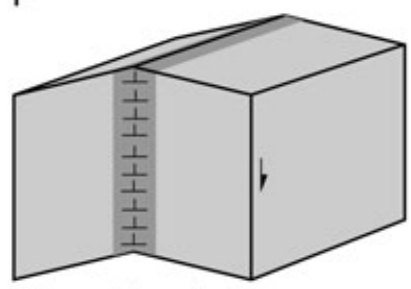

low-angle boundary (recovery $=$ glide + climb)

G
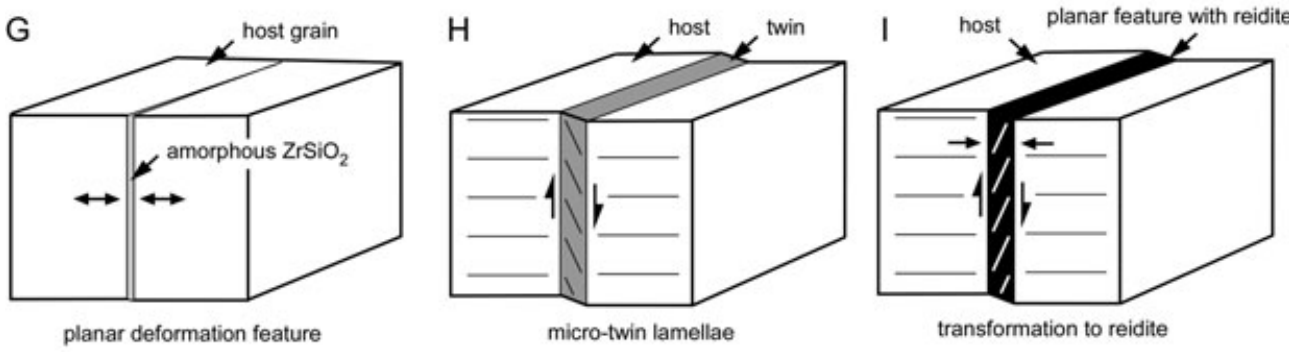

shock pressure(?)

Fig. 1. Schematic diagrams to illustrate the observed range in impact-related microstructures. Shaded parts of the diagrams indicate volumetric domains of modification of zircon. A) Nonplanar fractures. Dilated apertures can be filled with new zircon or impact melt of a different composition. Nonplanar fractures are not necessarily diagnostic of impact shock, and could form due to other processes. B) Planar fractures. Surfaces along which cohesion has been lost. C) Solid-state recrystallization. Arrows indicate the front of recrystallization. D-F) Crystal-plastic deformation. D) Distributed strain accommodated by dislocations. E) Microstructure accommodated by discrete low-angle boundaries and distributed dislocations. F) An energetically favorable scenario where dislocations have migrated into low-angle boundaries. Arrow indicating relative temperature refers to (D-F). G) Planar deformation features. A discrete, crystallographically controlled zone of lattice damage (amorphous material). H) Microtwin lamellae. These form along $\{112\}$ planes with $65^{\circ} /<110>$ relationship with host. I) Reidite lamellae. These form as microtwin lamellae within $\{100\}$ planar features in the host zircon with $[110] \mathrm{z}=[100] \mathrm{r}$ and $(112) \mathrm{z}=(100) \mathrm{r}$. Arrow indicating relative shock pressure refers to $(\mathrm{G}-\mathrm{I})$.

The presence of the high-pressure polymorph of $\mathrm{ZrSiO}_{4}$, reidite, was discovered by Reid and Ringwood (1969), and first confirmed in natural impact rocks by Glass and Liu (2001). The transformation to reidite, which is also tetragonal and has a scheelite structure (space group $\mathrm{I}_{1} / a$ ), is nucleated along $\{100\}$ planes in zircon via a simple shear mechanism such that $[110]_{\text {zircon }}$ becomes [100] reidite and (112) zircon aligns with (100) reidite. $_{\text {re }}$ (Fig. 1I) (Kusaba et al. 1985, 1986; Leroux et al. 1999). Reidite has been detected via Raman spectroscopy (Leroux et al. 1999; Gucsik et al. 2004). However, the exact form of reidite is not clear. The only direct evidence of reidite is via TEM of experimentally shocked zircon that shows microtwin lamellae of reidite within a planar microstructure parallel to $\{100\}$ in zircon (Leroux et al. 1999). The conditions for transformation of zircon to reidite are not well established. The transformation process is thought to begin at approximately $20 \mathrm{GPa}$ and be completed at approximately $53 \mathrm{GPa}$ (Kusaba et al. 1985; Fiske 1999; Leroux et al. 1999; Wittmann et al. 2006).

Shock metamorphism of zircon can also result in polycrystalline aggregates, or "granular-textured" zircon, which is interpreted to form by the recrystallization of incipient shock-induced diaplectic $\mathrm{ZrSiO}_{4}$ glass during high postshock temperatures (Bohor et al. 1993; Kamo et al. 
Table 1. SEM and EBSD settings and statistics.

\begin{tabular}{|c|c|c|c|c|c|c|}
\hline Technique & SEM & $\begin{array}{l}\text { Detector/acquisition } \\
\text { system }\end{array}$ & $\begin{array}{l}\text { Acc. } \\
\text { voltage }(\mathrm{kV})\end{array}$ & Probe current & $\begin{array}{l}\text { Working } \\
\text { distance } \\
(\mathrm{mm})\end{array}$ & Tilt $\left(^{\circ}\right)$ \\
\hline $\mathrm{CL}$ & Phillips XL30 (W-filament) & KE Developments & $10-12$ & Spot 6-7 & $15-17.4$ & 0 \\
\hline EBSD & $\begin{array}{l}\text { Zeiss Neon dual-beam FEG } \\
\text { (Figs. } 4 \text { and 5: Phillips } \\
\text { XL30 W-filament) }\end{array}$ & $\begin{array}{l}\text { Oxford Instruments } \\
\text { Channel } 5.9\end{array}$ & 20 & (XL30: Spot 5) & & 70 \\
\hline \multicolumn{7}{|c|}{ EBSD settings } \\
\hline \multicolumn{3}{|c|}{ EBSP collection time per frame (ms) } & \multicolumn{4}{|l|}{60} \\
\hline \multicolumn{3}{|c|}{ Background (frames) } & \multicolumn{4}{|l|}{64} \\
\hline \multicolumn{7}{|c|}{ EBSP noise reduction } \\
\hline \multicolumn{3}{|c|}{ Frames } & \multicolumn{4}{|l|}{4} \\
\hline \multicolumn{3}{|l|}{ Binning } & \multicolumn{4}{|l|}{$4 \times 4$} \\
\hline \multicolumn{3}{|l|}{ Gain } & \multicolumn{4}{|l|}{ High } \\
\hline \multicolumn{3}{|c|}{ Hough resolution } & \multicolumn{4}{|l|}{65} \\
\hline \multicolumn{3}{|c|}{ Match units } & \multicolumn{4}{|c|}{$\begin{array}{l}\text { Zircon }^{\mathrm{a}} \text {, reidite } \\
\text { (plus anorthite, Fig. 6) }\end{array}$} \\
\hline \multicolumn{3}{|c|}{ Band detection-No. bands } & \multicolumn{4}{|l|}{$6-8$} \\
\hline \multicolumn{3}{|c|}{ Data noise reduction } & \multicolumn{4}{|c|}{$\begin{array}{l}\text { "wildspike" removal, } \\
\text { five nearest neighbor } \\
\text { zero solution extrapolation }\end{array}$} \\
\hline
\end{tabular}

Note: SEM = scanning electron microscope; EBSD = electron backscatter diffraction; CL = cathodoluminescence; FEG = field emission gun.

${ }^{\mathrm{a}}$ Generated from zircon crystal structure at 9.8 Atm ( 1 MPa) (Hazen and Finger 1979).

1996; Glass and Liu 2001; Gucsik et al. 2004). This process is thought to occur during sustained shock and/or at high shock pressures. Pidgeon et al. (2007) reported an unusual lunar zircon aggregate texture (73235,82 zircon 1), where fragments of a sector-zoned grain reside in a "matrix" of younger low-crystallinity, high-U zircon. These authors interpreted the texture to have resulted from localized shock metamorphism, where the matrix represents diaplectic zircon glass. Decomposition of zircon to $\mathrm{SiO}_{2}$ and $\mathrm{ZrO}_{2}$ (baddeleyite) was first reported by Kleinmann (1969), and occurs at shock pressures and temperatures over $70 \mathrm{GPa}$ and $1775^{\circ} \mathrm{C}$, respectively (El Goresy 1965; Kusaba et al. 1985).

Despite the fact that the surface of the Moon has undergone multiple impact events, there have been no PDFs, PFs, granular textures, decomposition to baddeleyite or reidite reported in lunar zircon (Pidgeon et al. 2011). This could be symptomatic of comparatively few grains available for study (so far on the order of 100 grains) relative to the vast numbers of terrestrial impact grains studied.

This study focuses on zircon grains from lunar impact breccia samples $72215,73215,73235$, and 76295 recovered during the Apollo 17 mission. Deformation in these samples can be unequivocally attributed to formation during impact events, and are unlikely to be affected by tectonic or weathering processes such as could be found in terrestrial impact rocks. Most previous studies of lunar impact microstructures in zircon have relied on qualitative petrographic techniques, and there is no systematic analysis using modern quantitative microstructural techniques. This article redresses this issue by examining several different types of impactrelated microstructures in lunar zircon, to develop a conceptual framework for their formation.

\section{ANALYTICAL TECHNIQUES}

Petrographic thin sections were prepared by NASA. EBSD analysis required that samples were given a final polish with $0.06 \mu \mathrm{m}$ colloidal silica in $\mathrm{NaOH}$ for between 3 and $5 \mathrm{~h}$ on a Buehler Vibromet II polisher. Zircon grains were imaged in the scanning electron microscope (SEM) using SE, backscatter electron (BSE), and panchromatic cathodoluminescence $(\mathrm{CL})$ detectors. The SEMs used include a W-source Phillips XL30 SEM fitted with a CCD-Si CL detector, a W-source Zeiss EVO SEM, and a dual-beam field emission gun Zeiss NEON 40 SEM at the electron microscopy facility at Curtin University, Western Australia. SEM settings are summarized in Table 1. EBSD data were collected via automated mapping using an Oxford Instruments EBSD Channel 5 (SP9) acquisition system, including Nordlys detector. EBSD settings were optimized for zircon after Reddy et al. (2007, 2008), and are given with EBSD indexing statistics in Table 1. Theoretical match units for zircon (space group $\mathrm{I}_{1} /$ amd; Hazen and Finger 1979) and reidite (space group $\mathrm{I} 4_{1} / a$ ) were listed for the 
automated indexing of EBSD patterns. Feldspar was indexed in one map using anorthite match units in the HKL database within Channel 5 Flamenco software. All EBSD data were processed using Oxford Instruments Channel 5 software using procedures detailed elsewhere (Reddy et al. 2007). EBSD data were used to generate EBSD pattern property maps, crystallographic orientation maps, pole figures, and misorientation axis distributions. The plotting procedures have been described in detail elsewhere (Reddy et al. 2007). The results from each grain are ordered from the simplest to the most complex microstructures.

\section{RESULTS}

\section{Sample Descriptions}

The lunar impact samples in this study include 72215 from the rim of the Nansen crater (Marvin 1975; Ryder et al. 1975; Wood 1975; Nemchin et al. 2009), samples 73215 and 73235 from approximately $50 \mathrm{~m}$ east of the rim of Lara crater (Spudis and Ryder 1981; Ryder 1993), and breccia sample 76295, chipped from an ejecta boulder at station 6 (Meyer 1994).

\section{5,60 Zircon 4}

Sample 73235,60 is a fine-grained clast-rich aphanitic impact-melt breccia. It consists of a groundmass of plagioclase, pyroxene, opaque minerals, and rare spinel, and has lithic clasts strung out as schlieren within the dense matrix (James et al. 1975; Ryder 1993; Grange et al. 2011). Zircon 4 is a single subhedral grain clast, approximately $80 \mu \mathrm{m}$ across, with no internal zoning seen in SE or BSE images and a homogenous, dark CL response ("hexagon" grain of Grange et al. 2011). The grain records no variations in EBSD pattern quality (band contrast), and $<0.5^{\circ}$ crystallographic orientation variations (Fig. 2A).

\section{5, 122 Zircon 5}

This irregular-shaped grain occurs as an isolated clast about $60 \mu \mathrm{m}$ in length, and appears to be a fragment of a larger grain (Fig. 2B). The grain is uniformly dark in $\mathrm{CL}$, and numerous small fractures emanate from one edge. A discrete domain on one corner with low relief yields sufficiently poor EBSD band contrast that this region was not indexed (shown by arrow on Fig. 2Bii). Orientation mapping by EBSD shows approximately $10^{\circ}$ of cumulative crystallographic misorientation across the grain, distributed over tens of micrometers and aligned with $\{100\}$ and the long axis of the grain (Fig. 2B). The pole figure shows a smooth dispersion of crystallographic poles with a rotation axis parallel with $<001>$ (Fig. 2Bv).
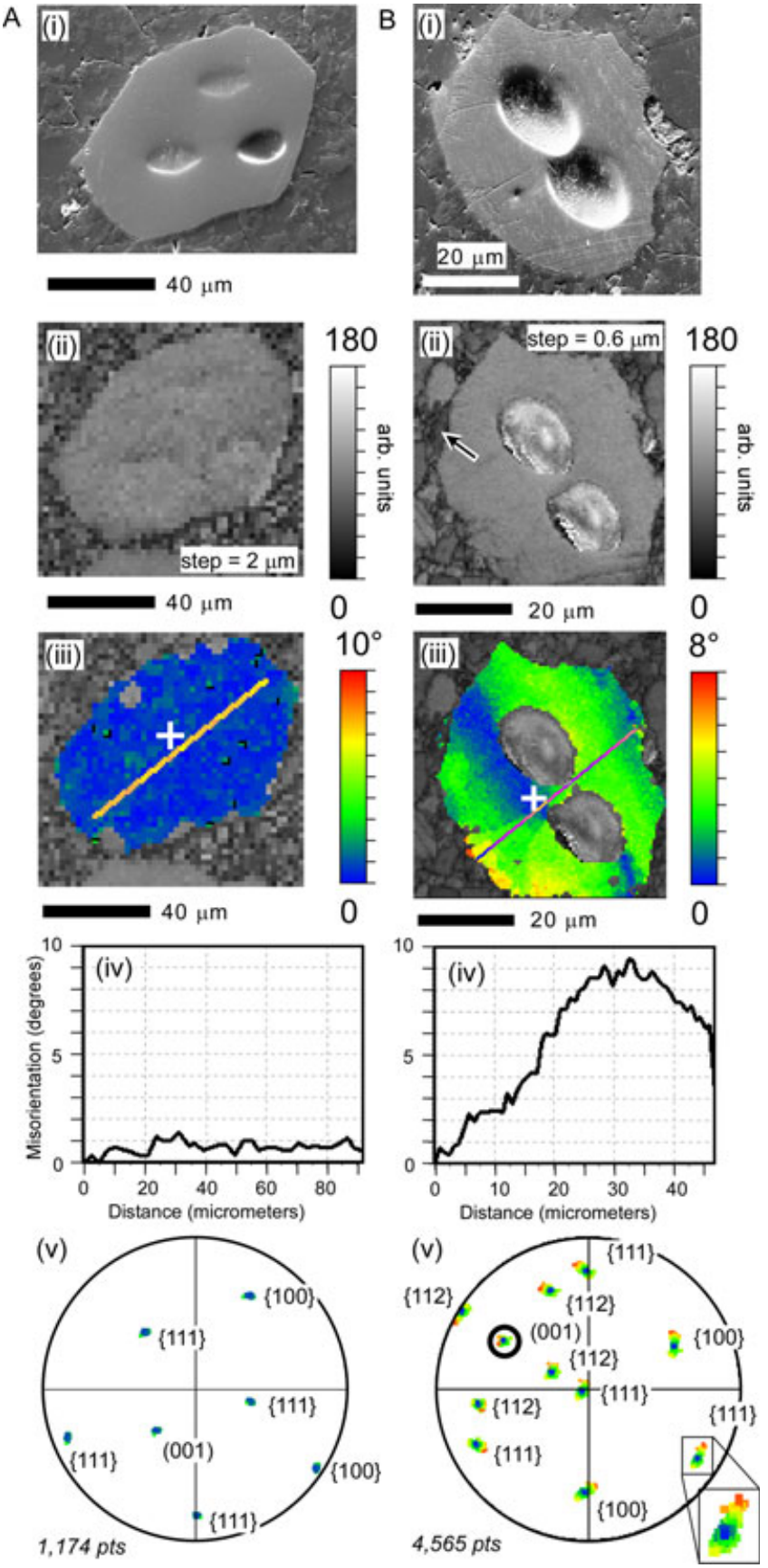

Fig. 2. A) Zircon 4 from 73235,60. B) zircon 5 from 73215,122. i) $\mathrm{SE}$ images. Elliptical pits are from in-situ ion microprobe analyses (Grange et al. 2011). ii) Electron backscatter diffraction band contrast map. Grayscale value indicates the contrast of the diffraction bands, and is a measure of EBSD pattern quality (white $=$ high quality). iii) Map of crystallographic orientation from EBSD data, colored for crystallographic orientation relative to a reference orientation (blue), defined by white cross, to $8^{\circ}$ or $10^{\circ}$ misorientation (red). iv) Cumulative misorientation profile along line shown in (iii). v) Stereographic projections of crystallographic poles for the EBSD data shown in (iii). Poles are predominantly dispersed around a single axis in (Biii) that coincides with $<001>$. Lower hemisphere equal area projections in sample $x-y-z$ coordinates. 

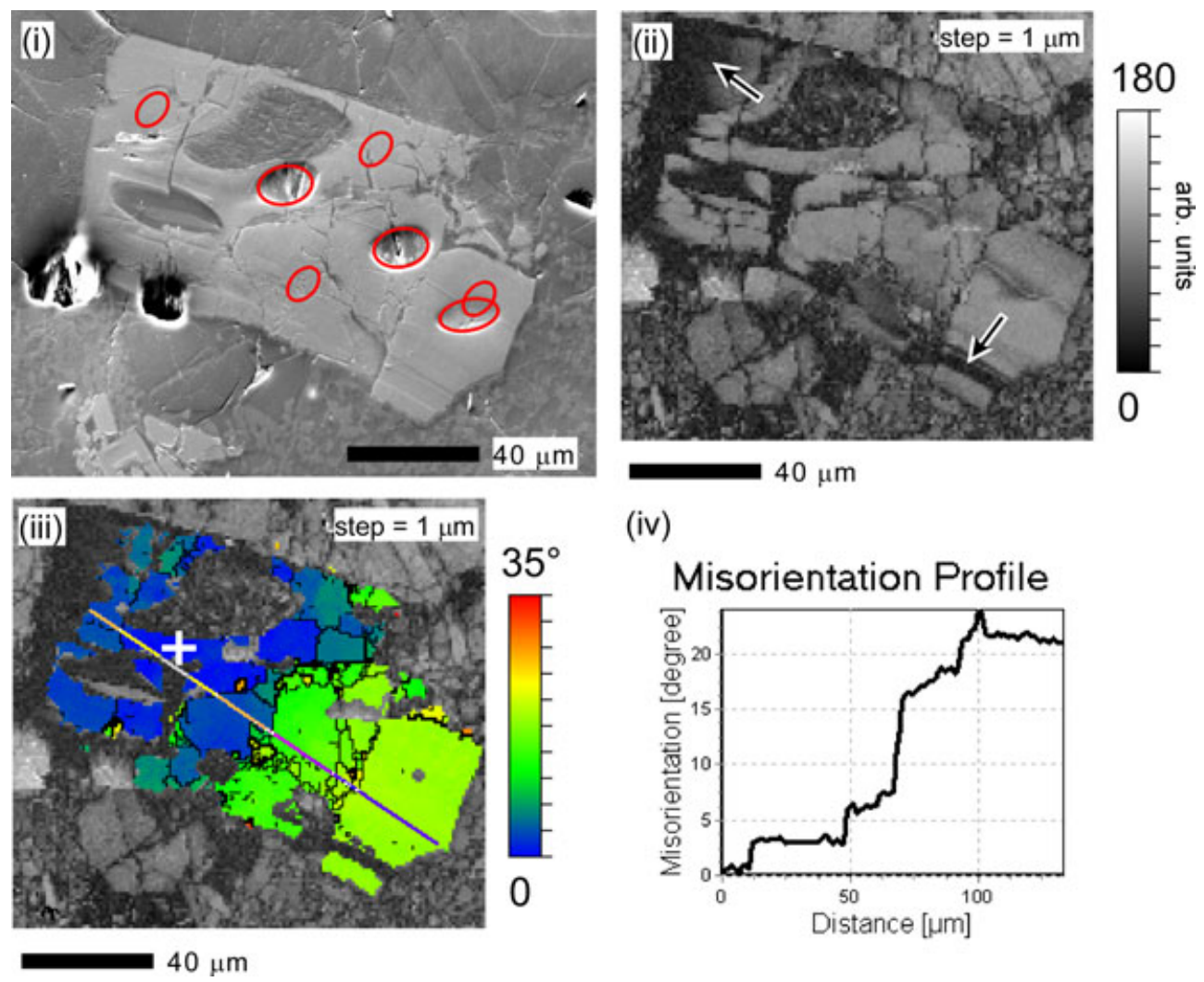

(iv)

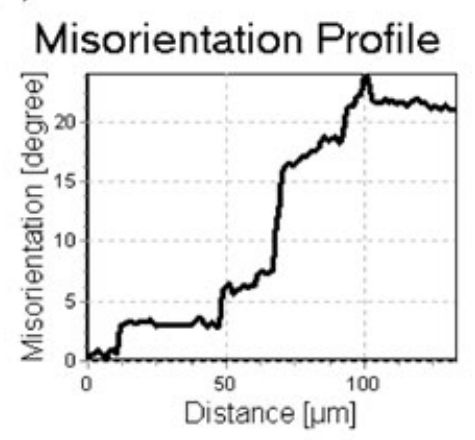

Fig. 3. Data for zircon 5 from 73235,60. A) SE image. Elliptical pits are from in-situ ion microprobe analyses (Grange et al. 2011). B) EBSD band contrast map. C) Crystallographic orientation map from EBSD data. White cross indicates reference orientation. D) Cumulative misorientation profile along line shown in (C).

\section{5,60 Zircon 5}

This is one of several grains enclosed within a felsic granophyre clast (Meyer et al. 1996). It is approximately $150 \mu \mathrm{m}$ across, has predominantly straight sides that are parallel to $\{100\}$, and contains rounded inclusions comprising aggregates of fine-grained silica and feldspar ("cracker" grain of Grange et al. 2011). SE imaging shows patchy domains of low relief that have characteristically poor-quality EBSD patterns that could not be indexed (Fig. 3). The grain is fragmented by a network of brittle fractures that offset the grain boundary. Orientation mapping by EBSD shows that the individual fragments do not contain internal crystallographic orientation variations, but have rotated relative to each other by several degrees (cumulatively $35^{\circ}$ across the grain).

\section{5,82 Zircon 1}

This is an aggregate of loosely interlocking subangular zircon grains enclosed in an anorthositic clast within breccia 73235 ("pomegranate" grain of Pidgeon et al. 2007) (Fig. 4). Zircon with low polishing relief occurs between many of the zircon fragments. This interstitial zircon yields very poor EBSD pattern quality, and could not be indexed. EBSD orientation mapping shows that the individual grains are randomly oriented relative to each other (Fig. 4). Some grains preserve gradational variations in crystallographic orientation, particularly at the edges of the grains that account for up to $10^{\circ}$ cumulative misorientation. However, these domains are not completely continuous from grain to grain (Fig. 4).

\section{5, 195 Zircon 1}

The oldest lunar zircon is in the clast-rich impactmelt breccia (72215) and has previously been described by Nemchin et al. (2009). It is approximately $550 \mu \mathrm{m}$ across and contains variations in birefringence that define primary zones (Fig. 5A). Nemchin et al. (2009) have shown that differences in $\mathrm{U}$ and $\mathrm{Th}$ between zones have resulted in varying degrees of radiation damage, which has locally reduced the refractive index and CL signal. The lack of well-developed crystal faces and truncation of sector and concentric zoning indicates that it is a relict fragment of a larger grain. Bright domains in CL correspond to the highest birefringence, low-U, low-Th sectors (Fig. 5B). EBSD pattern quality (band contrast) varies across the grain, coincident with 


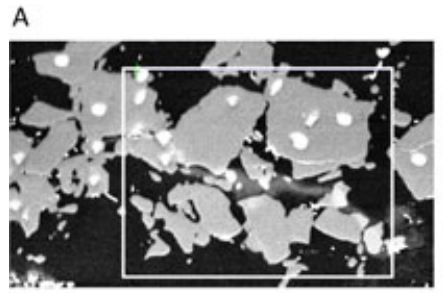

B

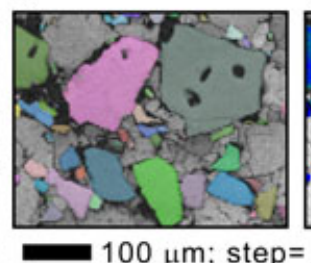

$\mathrm{F}$

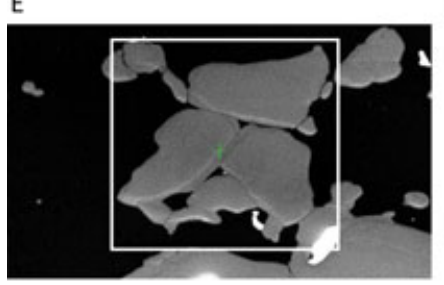

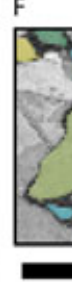

c

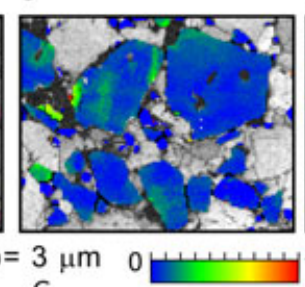

$\mathrm{G}$

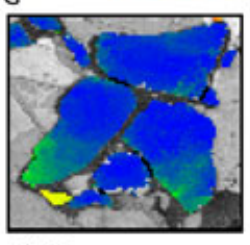

D
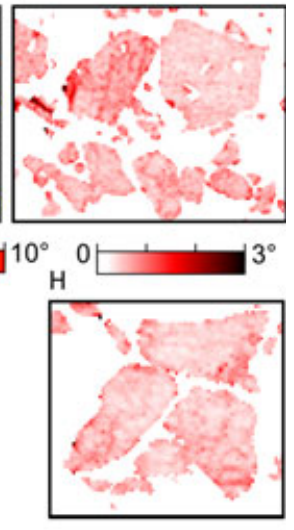

$50 \mu \mathrm{m} ;$ step $=1.5 \mu \mathrm{m}$

$50 \mu \mathrm{m} ; \mathrm{s}$

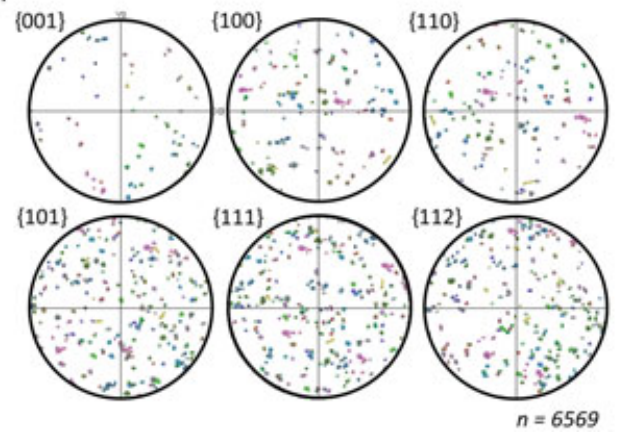

\section{J}

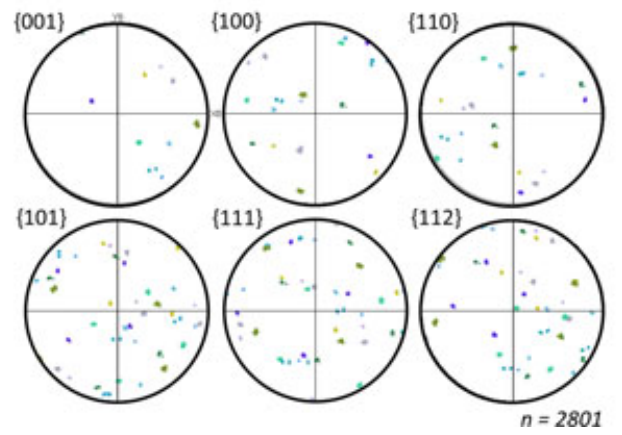

Fig. 4. Data for the zircon 1 aggregate in 73235,82. A) SE image. Bright spots are from in-situ ion microprobe analyses (Pidgeon et al. 2007). B) Orientation map from EBSD data with Euler colors to show crystallographic variations between grains (Reddy et al. 2007). Euler colors are defined by three color channels assigned to three Euler angles that describe the orientation. C) Orientation map to show the crystallographic variations within grains from a central reference orientation (blue) to misorientation of $10^{\circ}$ (red). D) Local misorientation map to show orientation gradients within grains. Each pixel is colored for mean misorientation (degrees) for each point and its immediate neighboring points $(3 \times 3$ local grid $)$. E) SE image of a detail of the aggregate. $\mathrm{F}-\mathrm{H})$ As in (B)-(D). I) Stereographic projections of crystallographic poles for the EBSD data shown in (B). J) Stereographic projections of crystallographic poles for the EBSD data shown in (F). (I) and (J) are lower hemisphere equal area projections in sample $x-y-z$ coordinates.

the sector zoning observed in the optical image. The low birefringence, high $\mathrm{U}$ and $\mathrm{Th}$ domains yield the poorest EBSD patterns, and could not be indexed (Fig. 5).

Orientation mapping reveals two orthogonal sets of deformation bands that cannot be seen using other imaging techniques (Fig. 5Di-ii). These cut across the primary zoning in the grain (Fig. 5D). The bands are oriented parallel to the trace of $\{100\}$. Changes in the sharpness of the bands can be observed that reflect transitions from gradational to discrete changes in crystallographic orientation along their length (Figs. 5D and $5 \mathrm{E}$ ). The deformation bands have misorientation axes parallel to $<001>$ (Fig. $5 \mathrm{~F})$.

\section{5, 122 Zircon 6}

This single grain consists of three rounded/lobate "arms," such that it resembles a propeller (Fig. 6). It is situated between three anorthite grains that, together with the zircon, form a rounded lithic clast in sample 73215. Sets of fractures that cut across the zircon and anorthite are clearly visible in SE imaging (Fig. 6A). Several sharply bounded, approximately $5 \mu \mathrm{m}$ wide domains of zircon with low polishing relief and poor EBSD pattern quality occur along the zircon-anorthite interface (indicated by arrows in Fig. 6B). The outermost parts of the three lobes also yield poor EBSD patterns with low percentage indexing. Two of these domains have straight boundaries parallel to (100) (white arrow heads in Fig. 6B), whereas the other boundary is gradational over approximately $20 \mu \mathrm{m}$. EBSD mapping reveals complex and heterogeneous variations in crystallographic orientation across the grain, characterized by gradational changes and discrete low-angle (mainly $<10^{\circ}$ ) boundaries (Fig. 6C). The cumulative misorientation accommodated by these microstructures is $24^{\circ}$ across the grain, predominantly by misorientation around $<001\rangle$ (Figs. 6C and 7). These microstructures are crosscut by brittle fractures, which do not accommodate 


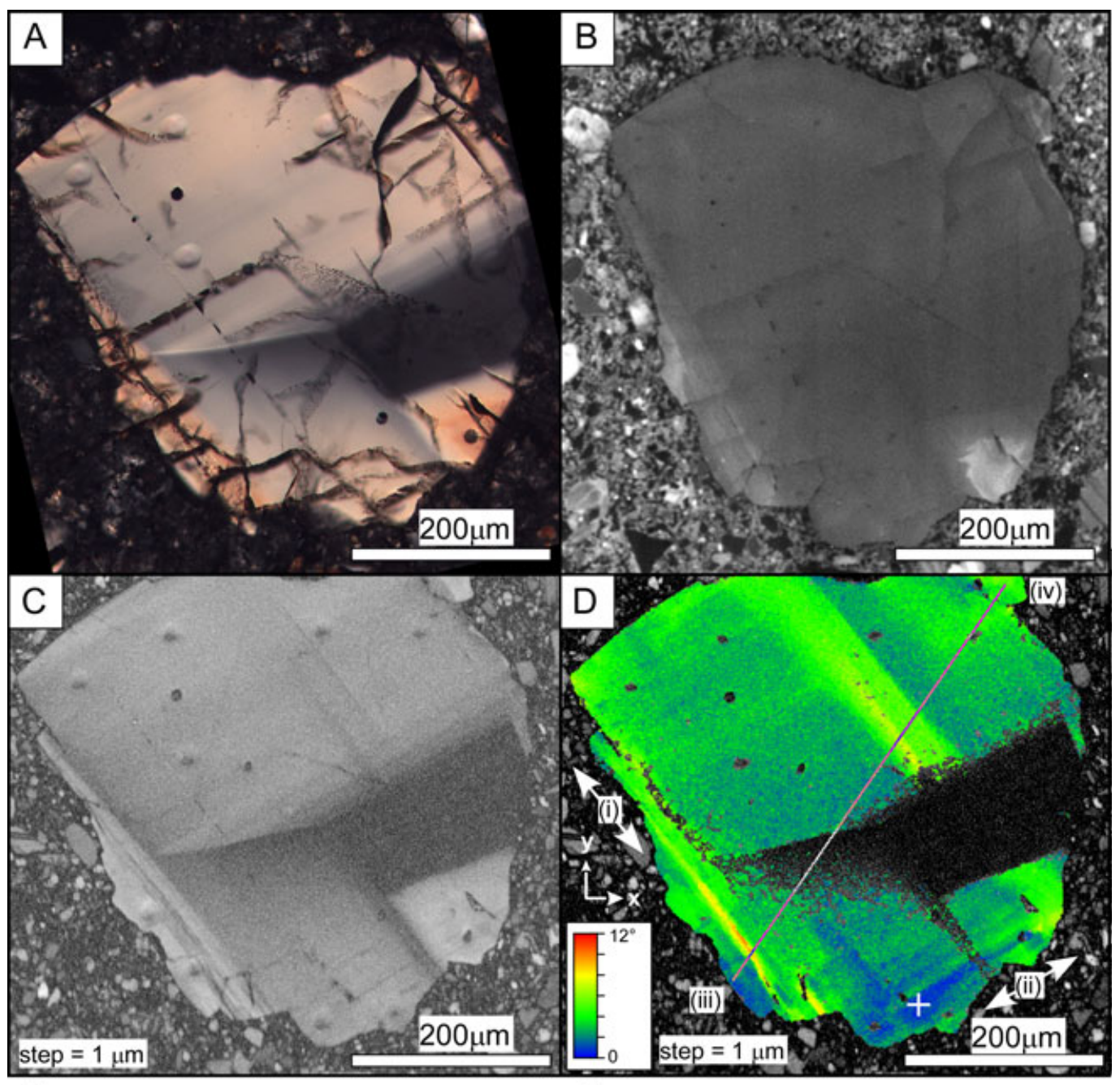

$E_{\text {(iii) }}$

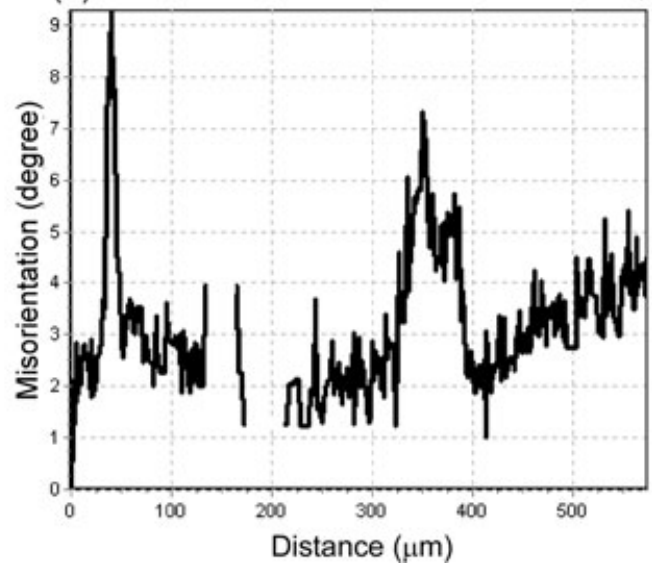

(iv) $\mathrm{F}$

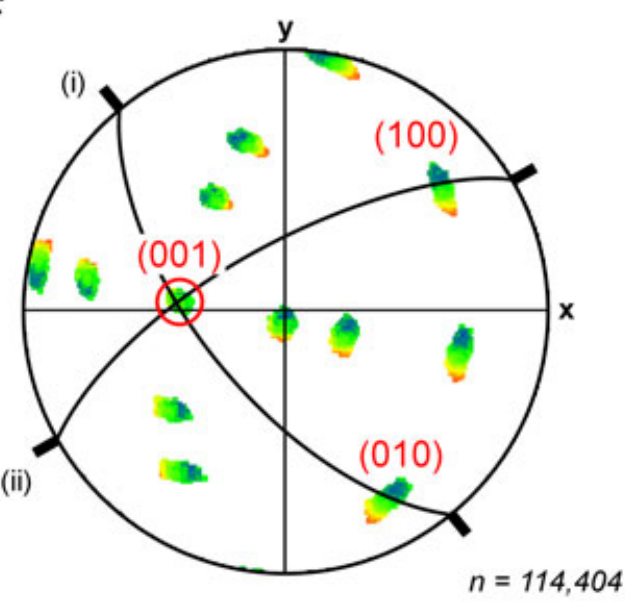

Fig. 5. Data for zircon 1 from 72215,195. A) Photomicrograph showing sector zoning defined by variations in birefringence. Elliptical pits are from in situ ion microprobe analyses (Nemchin et al. 2009). B) CL image. C) EBSD band contrast map. D) Orientation map from EBSD data to show the intragrain orientation variations. Each pixel is colored from reference orientation (blue, indicated by white cross to a misorientation of $12^{\circ}$ (red). Two sets of deformation bands are parallel to the trace of $\{100\}$ planes, indicated by arrows (i) and (ii). E) Cumulative misorientation profile along line (iii) to (iv) in (D). F) Pole figure of key crystallographic planes in zircon. Great circles are $\{100\}$ planes. Data are dispersed around a rotation axis parallel to $<001>$ direction. Data plotted as lower hemisphere equal area projections in sample $x-y-z$ coordinates. 


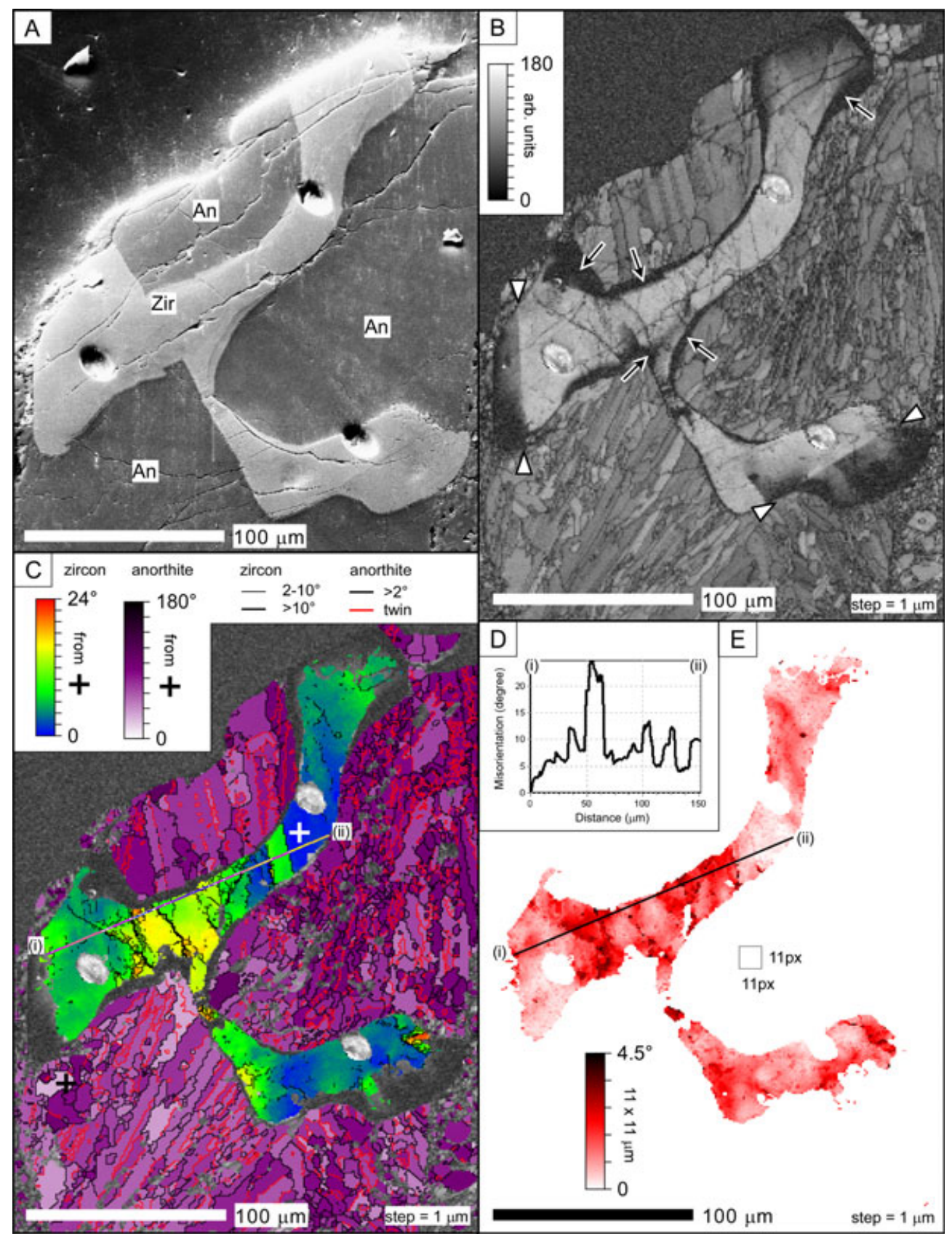

Fig. 6. Data for zircon 6 from 73215,122. A) SE image showing the grain between three anorthite grains. Elliptical pits are from ion microprobe analyses. B) EBSD band contrast map. Narrow domains at the grain interface indicated by the arrows yield low band contrast EBSD patterns. White arrows indicate sharp (100)-parallel boundaries to low band contrast domains. C) Orientation map from EBSD data to show variations in the intragrain orientation in the zircon and anorthite. Zircon is colored from reference orientation (blue), indicated by white cross, to a misorientation of $24^{\circ}$ (red). Anorthite colored for variations up to $180^{\circ}$. Boundaries between adjacent pixels with $>2^{\circ}$ misorientation are shown with solid lines (see legend). D) Cumulative misorientation profile along line (i)-(ii) shown in (C). E) Local misorientation map to show orientation gradients within grains. Each pixel is colored for mean misorientation (degrees) on a local $11 \times 11$ grid.

significant misorientation. The surrounding anorthite grains show complex internal microstructure that comprises subgrains and deformation bands, bound by low-angle $\left(<2^{\circ}\right)$ boundaries and deformation twins with a $180^{\circ}$ around $<001>$ relationship (Figs. $6 \mathrm{~B}$ and $6 \mathrm{C}$ ).

\section{5,59 Zircon 3}

This subrounded grain is approximately $250 \mu \mathrm{m}$ across and occurs in the aphanitic impact-melt breccia 73235 ("tiger" grain of Grange et al. 2011). SE imaging shows two discontinuous domains of high polishing relief and sharp, 

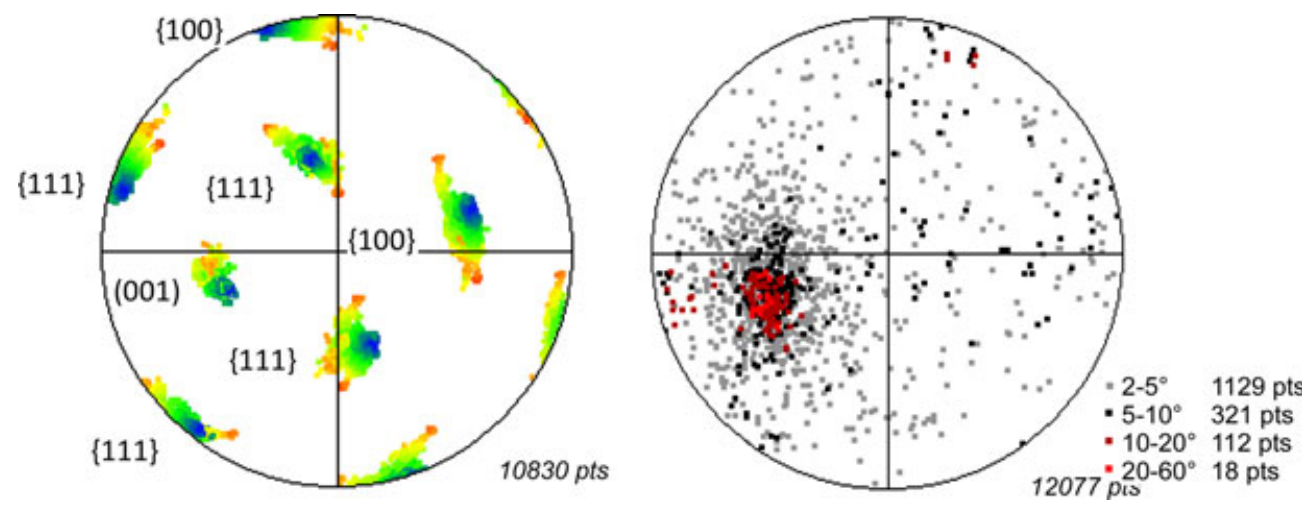

Fig. 7. Stereographic projections of crystallographic data shown in Fig. 6. A) Pole figure showing dispersion of poles around $<001>$ rotation axis. Data plotted as lower hemisphere projections in sample $x-y-z$ coordinates. B) Misorientation axis plot showing clustering of data around $<001>$ for all misorientation angles. Data plotted as lower hemisphere equal area projections in sample $x-y-z$ coordinates.

irregular boundaries at the rim of the grain (indicated by arrows in Fig. 8A). These domains are bright in CL and have strong EBSD patterns. The rest of the grain shows a subtle "wispy" CL pattern, with no concentric or sector zoning. The grain is cut by NPFs (Fig. 8B).

Parallel, straight, narrowly spaced bands cut across the grain and are visible in cross-polarized light (Fig. 8B). EBSD mapping shows these to be discrete, narrow ( $<100 \mathrm{~nm}$ to $\sim 2 \mu \mathrm{m}$ wide) domains of reduced EBSD pattern quality, that are interpreted to be PDFs (Figs. $8 \mathrm{~F}$ and $8 \mathrm{~J}$ ). They occur parallel to the traces of two different $\{112\}$ (Figs. 8 and 9). Their spacing is heterogeneous between and within the sets. One set typically occur as a composite or cluster of PDFs with 5-10 $\mu \mathrm{m}$ spacing (Figs. 8F and 8J). The widest PDFs contain zircon of a significantly different orientation to the host grain (Figs. 8G and 8K). Misorientation analysis reveals a $65^{\circ}$ around $\{110\}$ mismatch with the host grain, which is a known twin relationship in shocked zircon (Fig. 9) (Leroux et al. 1999). PDFs of the other set are spaced approximately $40-50 \mu \mathrm{m}$ apart, and also contain microtwins with a $65^{\circ} /\{110\}$ relationship (Figs. 8J and 9). Both sets of PDFs and microtwins cut across the patchy, CL-bright rim domains.

Orientation mapping shows that the grain preserves approximately $5^{\circ}$ of crystallographic misorientation (Figs. 8E and $8 \mathrm{H}$ ). In detail, this is accommodated across low-angle $\left(<1^{\circ}\right)$ boundaries that are parallel to (100) (Fig. 8K). This misorientation microstructure crosscuts the patchy bright $\mathrm{CL}$ rim domains, and intersects PDFs/microtwins (Figs. 8J and 8K). EBSD mapping also shows that the PDFs and microtwins have been locally annealed at the edge of the grain and adjacent to intragrain fractures to a distance of approximately $5 \mu \mathrm{m}$ (Figs. 8F, 8G, 8J, and 8K). In some instances, microtwins have been replaced with the host orientation once again.

\section{5,91 Zircon 2}

This grain is approximately $260 \mu \mathrm{m}$ long and occurs in the crystalline matrix of breccia 76295. It is featureless in SE images (Fig. 10), and contains an unusual sectorzoned core as seen in CL. The EBSD band contrast map shows that the grain contains five sets of differently oriented PDFs with similar morphology as found in 73235,59 zircon 3 (Fig. 10B). They occur parallel with the traces of two $\{112\}$, two $\{110\}$, and (001). They are heterogeneously developed across the grain with variable spacing (Fig. 10B). Orientation mapping shows that the grain has approximately $17^{\circ}$ cumulative misorientation (Fig. 10C). This is predominantly accommodated by planar low-angle $\left(<10^{\circ}\right)$ boundaries that coincide with planar features seen in the EBSD band contrast map (Figs. 10B and 10C). The grain also contains two twin orientations (Figs. 10C and 11A). Twins occur as small ( $<5 \mu \mathrm{m}$ wide), equant subdomains at the intersection of planar features with irregular low-angle boundaries, rather than as lamellae seen in 73235,59 zircon 3 . Misorientation analysis confirms that each twin orientation has a $65^{\circ} /[110]$ misorientation relationship, similar to microtwins in 73235,59 zircon 3 (Figs. 10C and 11). Less common are irregular low-angle boundaries and associated subgrains (Fig. 10C). Plots of the crystallographic poles for 76295,91 zircon 2 show a complex dispersion pattern of all poles, with no dominant dispersion axis (Fig. 11A).

\section{DISCUSSION}

\section{Impact Microstructures Preserved by Lunar Zircon}

\section{Fractures and Veins}

Nonplanar fractures are the most readily identifiable shock microstructure in zircon. Most lunar zircon grains are fractured to various degrees. At low strains, cracks 

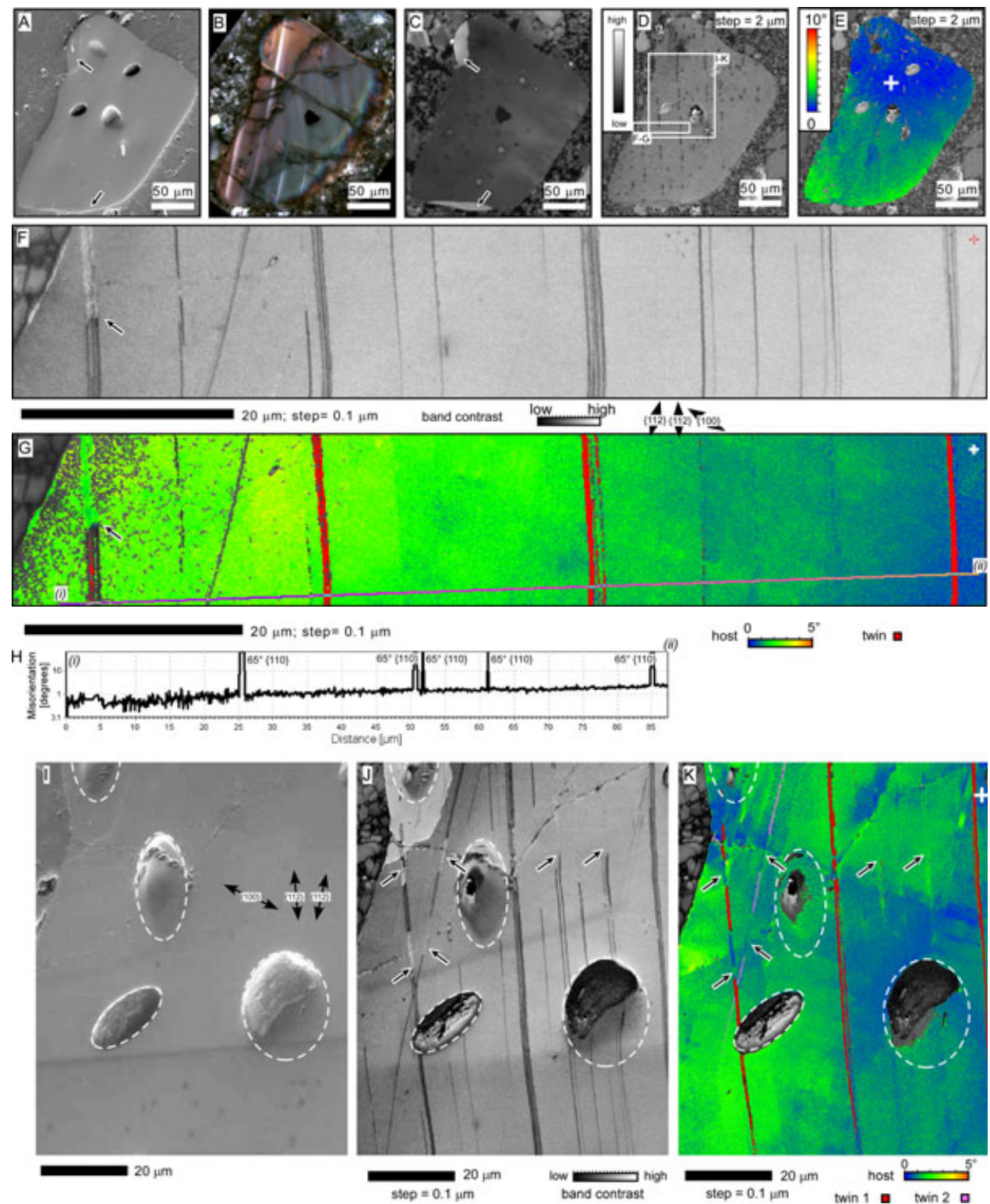

Fig. 8. Data for zircon 3 from 73235,59. A) SE image. Arrows indicate high relief domains. Elliptical pits are from in-situ ion microprobe analyses (Grange et al. 2011). B) Photomicrograph, cross-polarized light. C) CL image. D) EBSD band contrast map. E) Orientation map from EBSD data. White cross indicates position of reference point. F) High-resolution EBSD band contrast map of part of the grain highlighted in (D). The edge of the grain is at the top left of the image. G) Orientation map of area shown in (F) colored from reference orientation (blue), indicated by white cross, to a misorientation of $5^{\circ}$ (orange). Twin 1 domains are colored red. H) Cumulative misorientation profile along line (i)-(ii) shown in (G). I) SE image of part of the grain highlighted in (D). Oval pits are from ion probe analyses. J) High-resolution EBSD band contrast map. K) High-resolution orientation map from EBSD data. White cross indicates position of reference point. Color scheme as in $(\mathrm{G})$. An additional twin orientation (twin 2) shown in pink. Traces of key crystallographic planes are shown by arrows on (F) and (I). Locally annealed PDFs and twins are shown by arrows on $(F, G)$ and $(J, K)$.

form with little consequence on the internal microstructure. During impact events, block rotation of the fractured fragments may occur (e.g., Figs. 3 and 4). Open fractures have permitted localized static annealing of amorphous PDFs and microtwins adjacent fracture interfaces within 73235,59 zircon 3, locally lowering the stored strain energy (e.g., Fig. 8J). Static annealing is a thermomechanical recrystallization process (Humphreys and Hatherly 1996). Therefore, these fractures must have been pathways for heat exchange that provided the driving force for recrystallization. Fractures also enable melt to penetrate zircon grains (e.g., Figs. 1A, 1B, and 3). No crystallographically controlled PFs have been found in the zircon in this study, despite many differently 
A
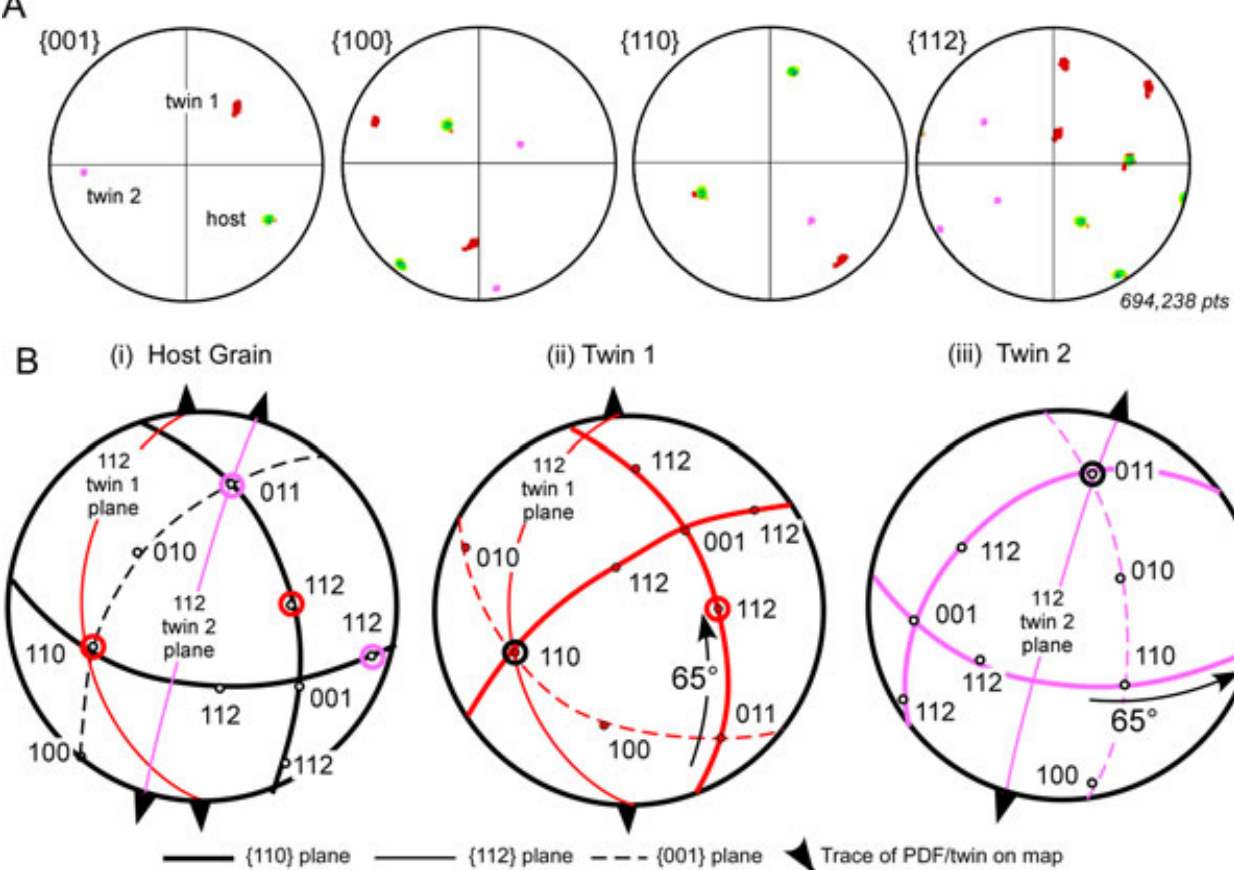

(ii) Twin 1

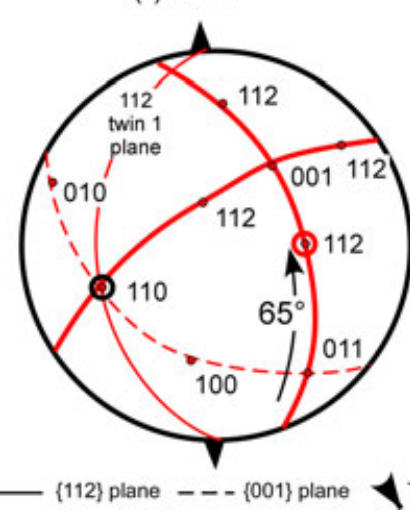

(iii) Twin 2

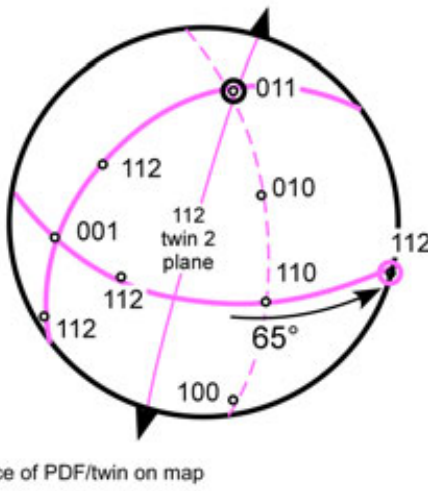

Fig. 9. Crystallographic data for zircon 3 from 73235,59. A) Pole figures of key crystallographic planes in zircon for data shown in Fig. 8G. Color schemes as in Fig. 8G. B) Plots to summarize the crystallographic relationships between (i) the host grain, (ii) twin 1 , and (iii) twin 2. Data plotted as lower hemisphere equal area projections in sample $x-y-z$ coordinates.

oriented PFs reported for terrestrial impact zircon (Fig. 12).

\section{Discrete Planar Features (PDFs, Microtwins, Reidite, Their Interrelationships)}

Planar microstructures, revealed by EBSD mapping as discrete $<5 \mu \mathrm{m}$ wide lines (and commonly composite lines) of reduced EBSD band contrast, are interpreted as shock-induced PDFs. Band contrast is a fundamental property of an EBSD pattern and is sensitive to variations in damage to the crystallographic lattice (Wilkinson 2000; Timms et al. 2010). Disorder at the scale of the electron-beam activation volume reduces pattern intensity such that high defect density domains yield degraded EBSD patterns, and amorphous material does not produce EBSD patterns. The samples do not have EBSD band contrast variations associated with surface topography generated by differential polishing. Therefore, the microstructures represent heterogeneously distributed crystallographic planes of localized damage. However, it is unclear from the EBSD band contrast criterion alone whether these features contain a higher defect density or diaplectic glass. 73235,59 zircon 3 and 76295,91 zircon 2 both preserve PDFs parallel to $\{112\}$ (Figs. 8 and 10). 76295,91 zircon 2 preserves additional sets of PDFs parallel to (001) and $\{110\}$, the latter having also been reported in experimentally shocked zircon (Figs. 9 and 12C). The most common spacing among different $\{h k l\}$ PDFs is between 0.1 and $8 \mu \mathrm{m}$ (Fig. 13). However, in grains where multiple sets of PDFs are developed, the spacing of PDFs formed along symmetrically equivalent crystallographic planes can vary substantially (Fig. 13), indicating that PDF spacing cannot be used in a simple way to indicate shock conditions.

The occurrence of PDFs along specific $\{h k l\}$ can be considered from elastic properties of zircon. The formation of PDFs, twins, and phase transformations must occur if yield conditions for plastic behavior (Hugoniot Elastic Limit) are exceeded. Minerals respond elastically before the plastic limit is reached, and therefore elastic behavior will probably exert some influence on the nature of the plastic strain component. For elastic materials, Young's modulus $(E)$ scales a longitudinal strain (or displacement), i.e., a kinematic impluse, into an equivalent stress, i.e., a dynamic response. Shear modulus $(G)$ describes the same relationship for shear strains, and shear stresses. Thus, high values of these moduli-the constants of proportionality in the equations that govern the moduli-reflect more stress "response" for a given strain (or displacement) "input." Zircon is highly anisotropic in its elastic properties, such as its Young's modulus ( $E$ is $63.4 \%$ ) and Shear modulus ( $G$ is $20.7 \%$ ) (Fig. 14) (Hearmon 1984). The directions normal to all the PDF plane orientations reported here and elsewhere always coincide with high values of Young's modulus 


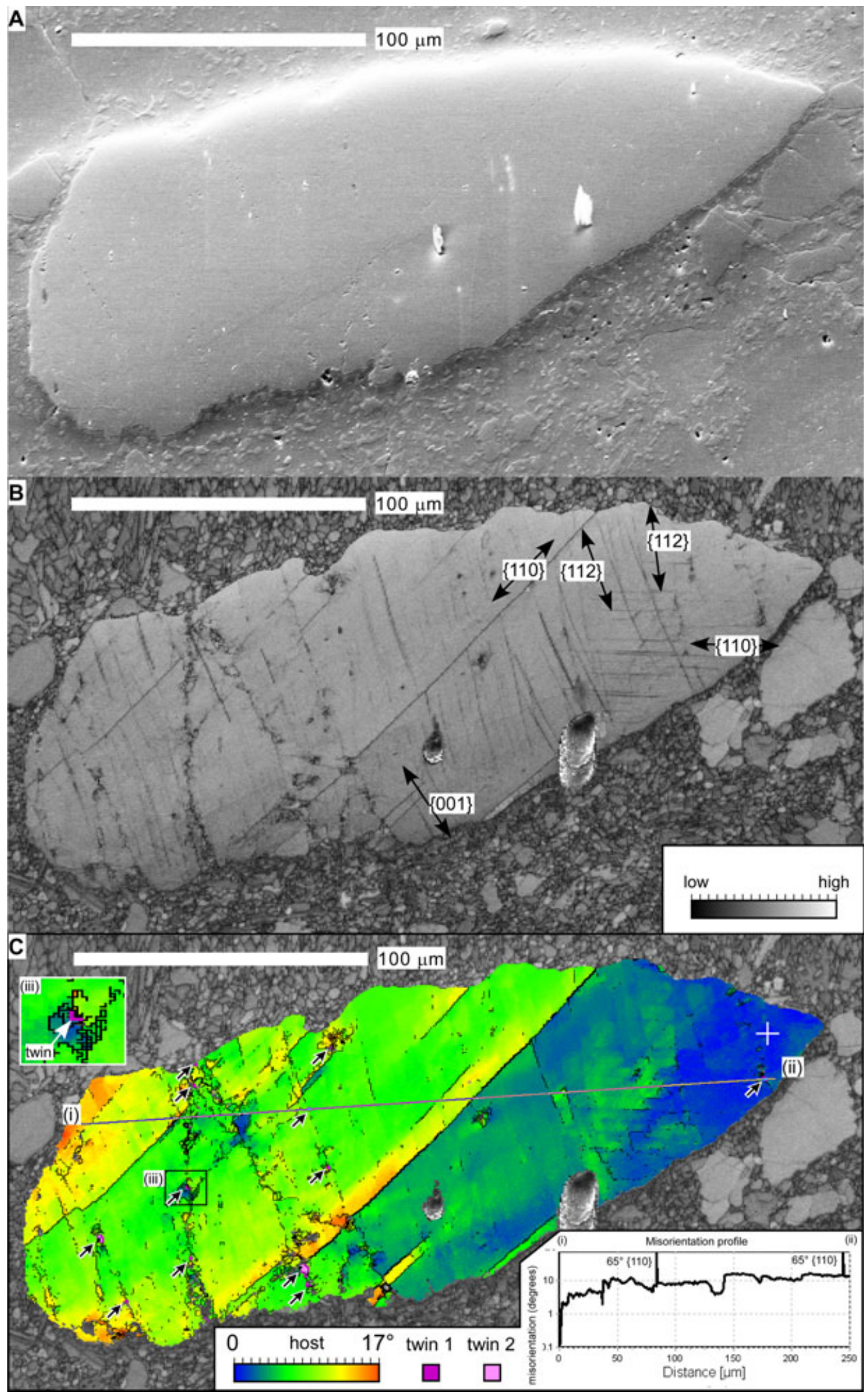

Fig. 10. Data for zircon 2 from 76295,91. A) SE image. B) EBSD band contrast map. Traces of crystallographic planes are indicated by arrows. C) Orientation map from EBSD data to show intragrain crystallographic orientation variations from a reference point indicated by white cross (blue) to $17^{\circ}$ misorientation (orange). Twin orientations 1 and 2 are colored purple and pink, respectively. Misorientation profile along line (i)-(ii) is shown in lower right. iii) An example of a twin domain (inset). 
A

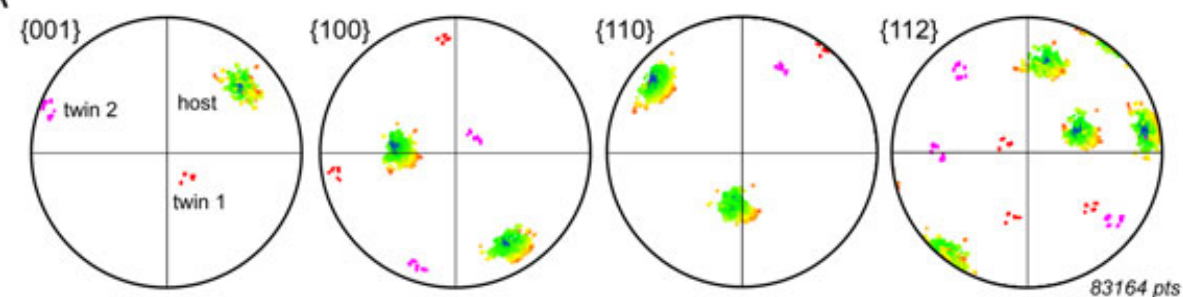

B

(i) Host Grain

(ii) Twin 1

(iii) Twin 2

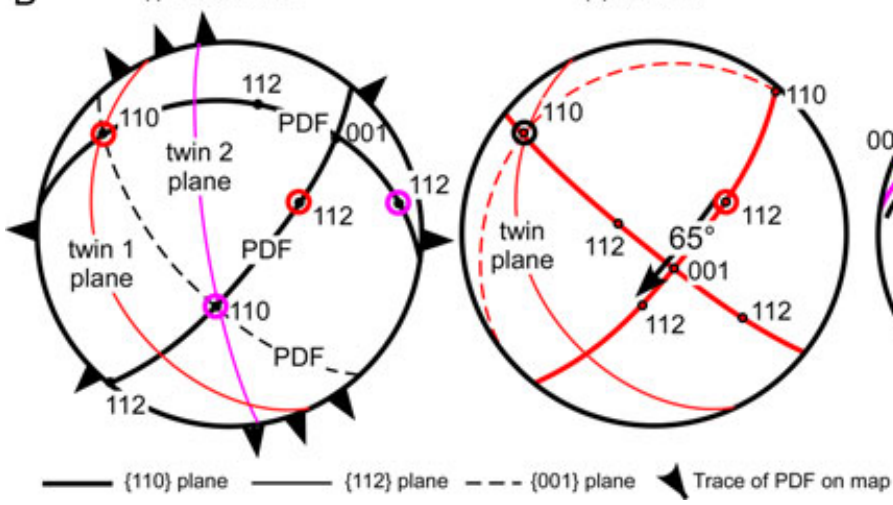

Fig. 11. Crystallographic data for zircon 2 from 76295,91. A) Pole figures of key crystallographic planes in zircon for data shown in Fig. 10C. Color schemes as in Fig. 10C. B) Plots to summarize the crystallographic relationships between (i) the host grain, (ii) twin 1, and (iii) twin 2. Data plotted as lower hemisphere equal area projections in sample $x-y-z$ coordinates.

(Fig. 14). That is, zircon is elastically "softest" in directions perpendicular to the PDF planes. However, PDF planes do not always align normal to directions with high shear modulus $\left(G_{\max }\right.$; Fig. 14B). This suggests that Young's modulus anisotropy has the greatest influence on the selection of PDF planes (i.e., (001), $\{110\},\{112\}$, $\{320\}$ ), and that they are (predominantly) compression/ extensional damage planes. The exact planes that form PDFs (and presumably their spacing) will depend on the direction(s) and intensity of the shock waves that propagate through the grain.

Within 73235,59 zircon 3 and 76295,91 zircon 2, the host-twin geometric relationship is described by $65^{\circ}$ rotation around a $\langle 110\rangle$ direction. This follows the same symmetry relationship as those generated in laboratory shock-deformation experiments and terrestrial shocked zircon (Figs. 9 and 11) (Leroux et al. 1999; Moser et al. 2011). In 73235,59 zircon 3, microtwin lamellae occur within $\{112\}$-parallel PDFs, and the $<110>$ "apparent" rotation axis is aligned along the lamellae plane (Figs. 8 and 12D). In this configuration, $65^{\circ}$ is exactly the amount of rotation required to translate $<112\rangle$ directions along a $\{110\}$ plane. However, the twin mechanism is most likely a martensitic (shear) transformation that involves shortrange lattice reconfiguration and requires considerably $<65^{\circ}$ actual rotation. The fact that twinned zircon is only found in the widest $\{112\}$ PDFs and "die out" along their length as these microstructures become narrower suggests that twins and $\{112\}$ PDFs are genetically related, and probably form synchronously. $\{112\}$ in zircon are special in that they contain high shear modulus $\left(G_{\max }\right)$ values and are normal to directions of high Young's modulus (Fig. 14). This permits the formation of shear twins along $\{112\}$ PDFs. Shear twins are likely to form along optimally orientated $\{112\}$ planes for maximum shear stress, possibly at $45^{\circ}$ to the maximum principal stress (shock wave direction). However, this remains to be verified. The fact that some planar features contain a combination of amorphous and twinned material could suggest that these $\{112\}$ planes were oriented oblique to the shock wave(s) such that both twinning and the formation of amorphous material could occur. Alternatively, the narrower, nontwinned domains represent "tip" (or "process") zones where the shock energy was not sufficient to displace the lattice to form a twin. In these zones, the lattice is locally damaged enough to reduce the EBSD band contrast, and cause subtle changes to optical properties.

In 73235,59 zircon 3, twinned PDFs are spaced more widely than nontwinned PDFs (Figs. 8 and 13). No twins occur in PDFs parallel to other planes (neither in 76295,91 zircon 2 nor experimentally by Leroux et al. 1999), which is probably due to the lack of a viable twin law and low shear modulus along those planes. For example, $\{110\}$ PDFs have very low $G_{\max }$ and do not form shear twins. In 


\section{A Dislocation Slip Systems in Zircon}

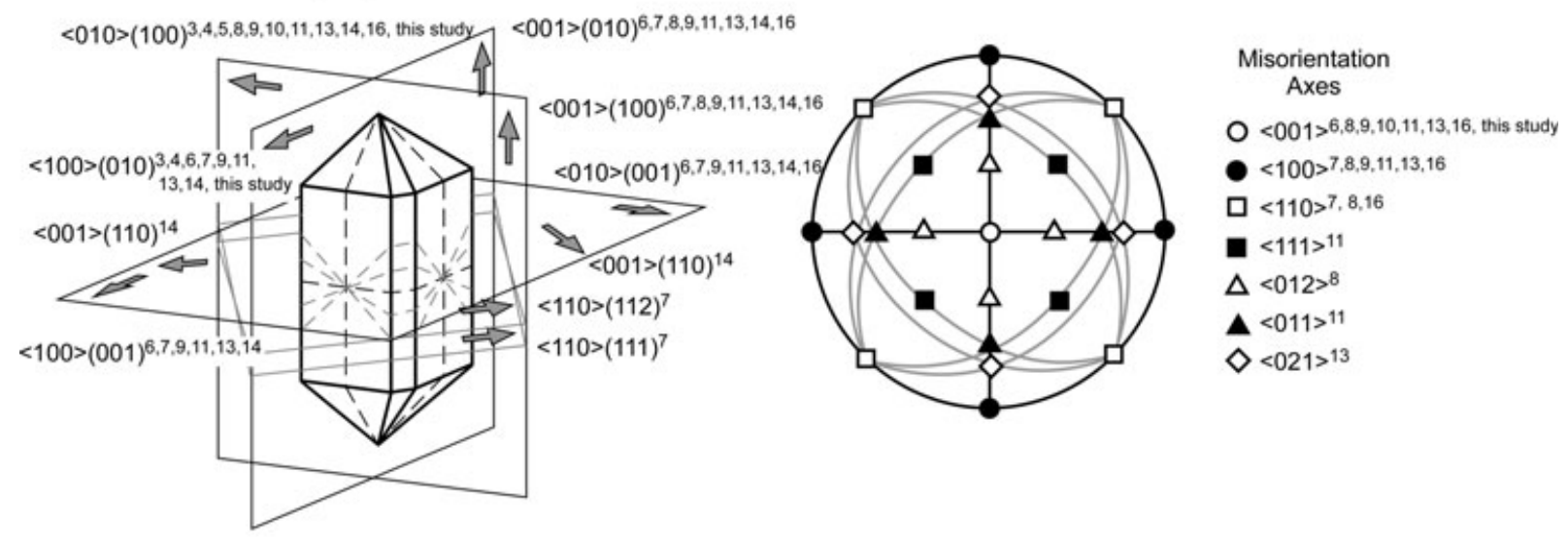

B Planar Fractures (PFs)

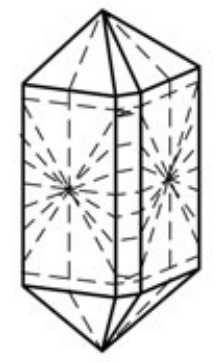

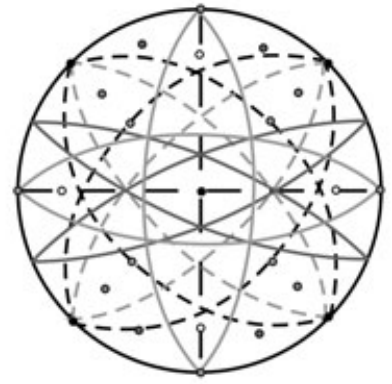

$-\{001\}^{12}-\{201\}^{3}$

- $\{100\}^{3,12}--\{211\}^{3}$

$--\{111\}^{3}-\{221\}^{3}$
C Planar Deformation Features (PDFs)

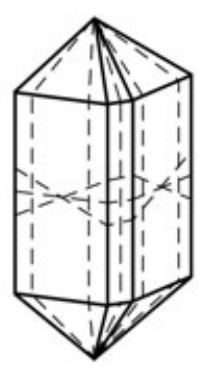

- $\{001\}^{15, \text { this study }}$

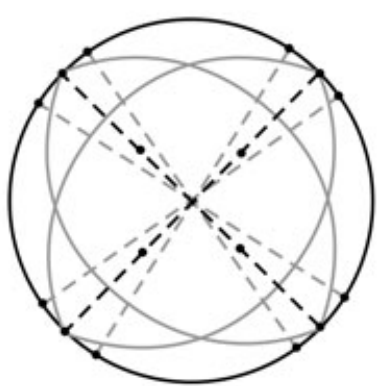

- - $\{110\}^{3}$ (60GPa), this study

- $\{112\}^{15, \text { this study }}$

$--\{320\}^{3(40 \mathrm{GPa})}$
D Micro-twin Lamellae

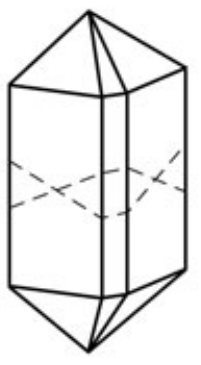

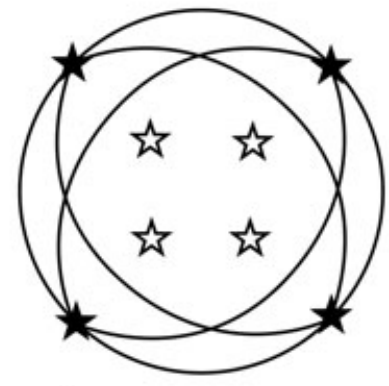

$65^{\circ}<110>^{3,15}$, this study

\ $\langle 112\rangle_{h}=\langle 112\rangle_{t}^{\text {this study }}$

- $\{112\}$ twin plane ${ }^{3, \text { this study }}$
E Reidite Lamellae
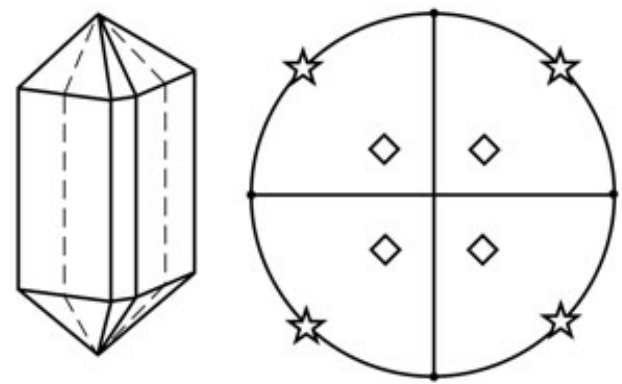

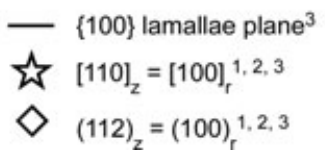

Fig. 12. Schematic diagrams to show the crystallographic orientation of deformation microstructures in zircon. Crystal views are dominated by $\{100\}$ and $\{101\}$ facets and minor $\{110\}$ and $\{111\}$ facets. Stereographic projections are lower hemisphere equal area projections. A) Dislocation slip systems in zircon. B) Planar fractures. C) Planar deformation features. D) Microtwin lamellae. E) Reidite lamellae. References: 1 = Kusaba et al. (1985); 2 = Kusaba et al. (1986); 3 = Leroux et al. (1999); $4=$ Reimold et al. (2002); $5=$ Reddy et al. (2006); $6=$ Timms et al. (2006); $7=$ Reddy et al. (2007); $8=$ Reddy et al. (2009); $9=$ Moser et al. (2009); 10 = Nemchin et al. (2009); 11 = Timms and Reddy (2009); 12 = Cavosie et al. (2010); 13 = Timms et al. (2011); $14=$ Kaczmarek et al. (2011); $15=$ Moser et al. (2011); $16=$ Timms et al. (Forthcoming). 

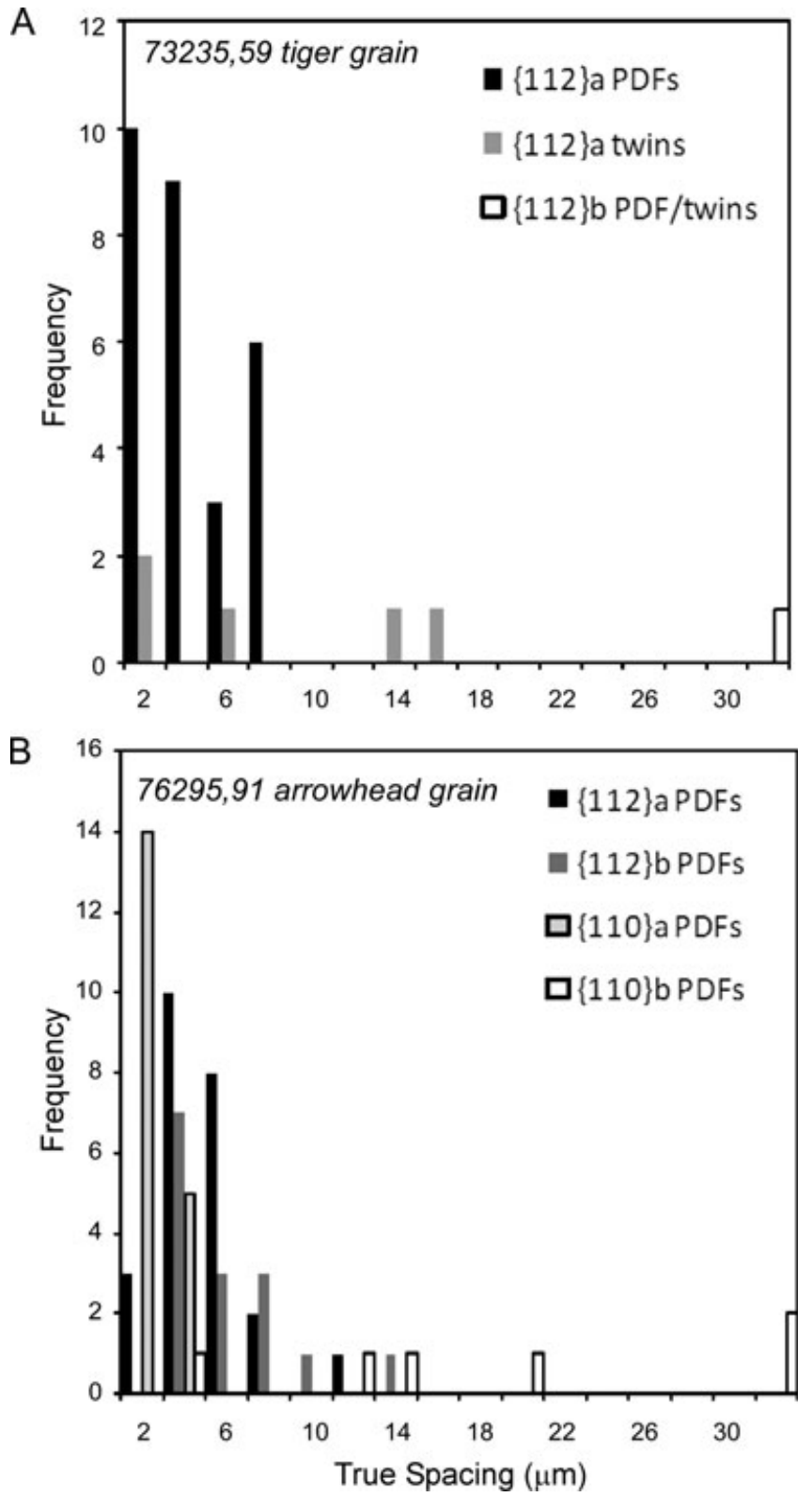

Fig. 13. A) Histogram of the spacing of PDFs and microtwin lamellae in 73235,59 zircon 3. True spacing was determined from distance measured from Figs. $8 \mathrm{~F}$ and $8 \mathrm{~J}$, corrected for the orientation of the PDF plane in Fig. 9B. B) Histogram of PDF spacing for 76295,91 zircon 2, using data derived from Figs. 10B and 11B.

contrast to 73235,59 zircon 3 , the morphology of the twinned domains in 76295,91 zircon 2 is isolated and equant, and occurs at the intersection of two or more deformation microstructures. It is plausible that these twins formed at sites of locally high shear stress that correspond to the intersection of oblique microstructures (e.g., subgrain boundaries) that interacted during a shock event, possibly by a boundary dissociation mechanism (Humphreys and Hatherly 1996).

\section{A Youngs Modulus (E) Anisotropy}

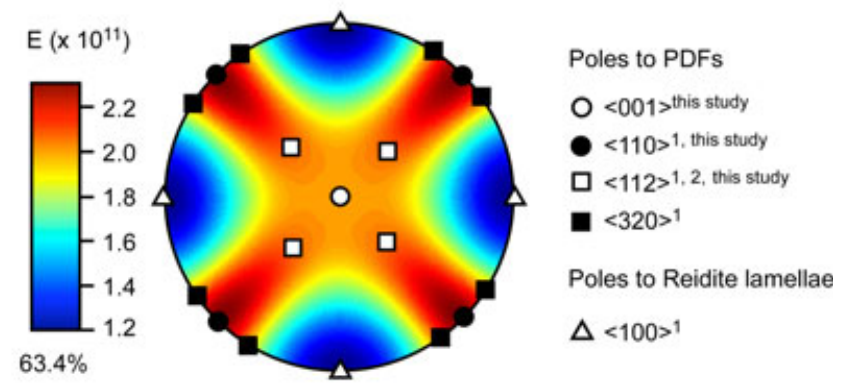

B Maximum Shear Modulus $\left(G_{\max }\right)$ Anisotropy

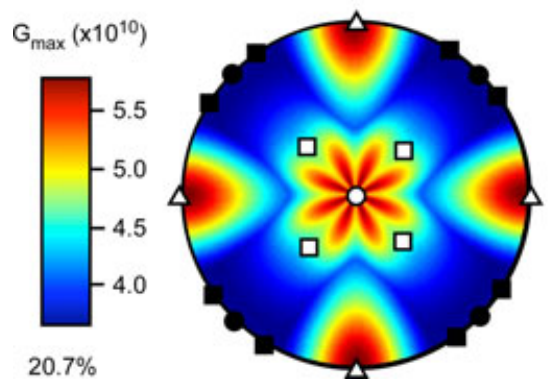

Fig. 14. (A) Stereographic projection of Young's modulus $(E)$ anisotropy and (B) maximum shear modulus $\left(G_{\max }\right)$ anisotropy for zircon. The anisotropy tensors were calculated using the elastic constants of Hearmon (1984) using formulation adapted for zircon from Turley and Sines (1971). Projection in (A) is contoured for longitudinal strain per unit longitudinal stress. (A) and (B) are annotated with the poles to PDF planes, and reidite lamellae in zircon. Note that $\{112\}$ can contain microtwin lamellae. References: 1 = Leroux et al. (1999); $2=$ Moser et al. (2011).

In zircon, $\{100\}$ corresponds to the minima of $E$ and maxima of $G\left(G_{\max }\right)$ (Fig. 14). Leroux et al. (1999), Cavosie et al. (2010), and Moser et al. (2011) reported PFs in $\{100\}$. However, there are no reports of $\{100\}$ PDFs in zircon. This could be because the localization of longitudinal damage planes is inhibited along $\{100\}$ (they have low plane-normal Young's modulus), which could be a pre-/corequisite facilitation for the nucleation of shear transformations. The fact that shock pressures over approximately $20 \mathrm{GPa}$ are required to transform zircon to reidite along $\{100\}$ suggests that this difficulty can be overcome at high shock pressure conditions. If present, reidite should be detectable by EBSD due to the difference in lattice parameters. However, there are currently no reported occurrences of reidite in lunar samples (Fig. 12E). This could be due to the limited number of lunar zircons analyzed relative to extensive research on terrestrial and experimentally shocked zircon.

\section{Dislocation Creep Microstructures}

Variations in crystallographic orientation are common in lunar zircon, and are seen in all grains except 
73235,60 zircon 4 and 73235,60 zircon 5. Where rotation due to fracturing can be eliminated, these textures are attributed to crystal-plastic deformation in which the crystallographically controlled formation and migration of dislocations result in long-range distortions of the crystal lattice, as shown by 732215,122 zircon 5 (Figs. 1D and 2B). The crystallographic misorientation at the margins of some grains in the 73235,82 zircon 1 aggregate could be due to crystalplastic deformation preceding fracturing/fragmentation of a single grain, or stresses associated with impingement of the grains at high temperatures. 73215,122 zircon 6, 73235,59 zircon 3, 72215,195 zircon 1, and 76295,91 zircon 2 show a deformation microstructure comprising a combination of gradational lattice distortion and discrete low-angle boundaries. Generally, the migration of dislocations into energetically favorable low-angle boundaries is facilitated by temperature (Figs. 1E-F). The most characteristic and commonly occurring impact-related crystal-plastic microstructures in the lunar zircon are planar deformation bands parallel to $\{100\}$ planes with $<001>$ misorientation axes (e.g., Figs. 5D and $5 \mathrm{~F}$ ). This geometry is consistent with a dislocation glide system with $<100>\{010\}$ slip, also observed in terrestrial impact-related zircon (Fig. 12A) (Leroux et al. 1999; Reimold et al. 2002; Moser et al. 2009).

\section{Discrete Domainal Features (Recrystallization Fronts, Amorphous Zones)}

Recrystallization textures are characterized by irregular boundaries, patchy development along rims, truncation of primary zoning, bright $\mathrm{CL}$, and relatively strong EBSD patterns. This texture can be seen in 73235,59 zircon 3 (Fig. 8). Recrystallization domains are the product of solid state alteration (Putnis 2002), and result in the volumetric replacement of crystalline host zircon by new zircon (Fig. 1C). Discrete, nonplanar domains of amorphous zircon can been seen at the interfaces of fractures and phase boundaries, for example, in the interstitial zircon of the 73235,82 zircon 1 aggregate (Fig. 4) and heterogeneously along the margin of 73215,122 zircon 6 (Fig. 6). In both cases, these domains have sharp boundaries and higher $\mathrm{U}$ and $\mathrm{Th}$ concentrations (and lower $\mathrm{Th} / \mathrm{U}$ ) than the adjacent zircon (Pidgeon et al. 2007; Grange et al., unpublished data). However, it is not entirely clear whether the loss of crystallinity of 73215,122 zircon 6 (1) occurred by the formation of diaplectic $\mathrm{ZrSiO}_{4}$ glass at the time of impact (true amorphization), or (2) is the result of radiation damage accumulated since the event (recrystallization/growth of high $\mathrm{U}$ and Th zircon, plus subsequent metamictization).

\section{Framework for the Formation of Impact Microstructures}

Empirical data from laboratory experiments provide loose constraints on the pressure-temperature stability fields for minerals in the $\mathrm{ZrSiO}_{4}$ system (Fig. 15A) (Stubican and Roy 1963; Taylor and Ewing 1978; Fukunaga and Yamoaka 1979). With the exception of the zircon-reidite phase transformation and decomposition of zircon to $\mathrm{ZrO}_{2}$, there are surprisingly few constraints on the environmental conditions at which the other impactrelated microstructures form. Wittmann et al. (2006) recorded the relative proportions of different shock microstructures in zircon from different parts of several terrestrial impact sites. They combined these data with constraints from laboratory experiments and modeled pressure-temperature histories to develop a framework for the progressive stages of shock history. However, their scheme involves an approximate linear relationship between shock pressure and postshock temperature. Here, published constraints with reasonable assumptions of conditions are used to construct a conceptual framework for the formation of impact-related microstructures in zircon in a pressure-temperature-time space (Fig. 15). This framework is then used to investigate relationships between impact-related microstructures from spatially different locations relative to an impact event.

The available data permit the development of schematic "deformation mechanism maps" for impact events, in which temperature-pressure space is divided into fields that represent the dominant impact microstructures (Fig. 15) (Ashby 1972; Frost and Ashby 1982). Fractures (NPFs and PFs), PDFs, twins, and reidite formation require high strain rates. The prevalence of NPFs and lack of the latter microstructures in nonimpact settings suggest that NPFs can form at low differential stress, low strain rate conditions associated with tectonic activity, cooling and volume change associated with metamictization. The formation of shock-related PFs requires tensile or shear stresses, high strain rates found at impact conditions. If $\mathrm{PFs}$ are a direct shock effect, then the timeframe for their formation can be much less than a few seconds (Langenhorst and Deutsch 1994). PDFs most probably result from longitudinal shock stresses. Microtwin lamellae form along $\{112\}$ PDFs that are favorably oriented such that the critically resolved shear stress is sufficiently above a threshold value to activate twinning. Similarly, the formation of reidite lamellae must require favorably oriented $\{100\}$ planes with the additional requirement of confining pressures above approximately $20 \mathrm{GPa}$ (Kusaba et al. 1985; Fiske 1999; Leroux et al. 1999; Wittmann et al. 2006). Solid-state recrystallization and repair of crystallographic damage (annealing) are 

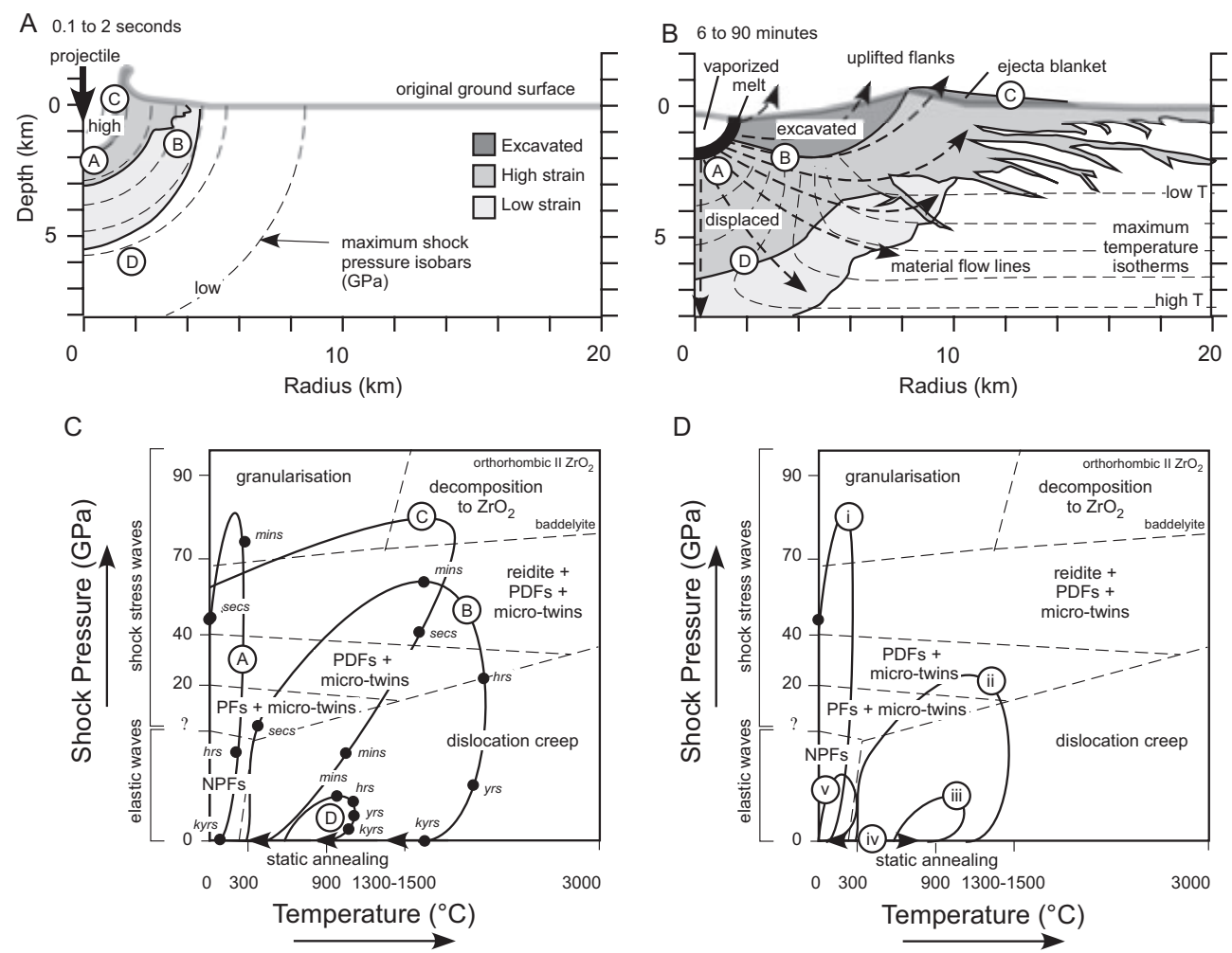

Fig. 15. A) Schematic cross section of the initial compression stage of a $10 \mathrm{~km}$ diameter crater forming impact event $(0.1-2 \mathrm{~s}$ elapsed after impact). Shock pressure isobars adapted from Melosh (1989). B) Schematic cross section of event shown in (A) during crater excavation stage (6-90 min after impact). Strain distribution in (A) and (B) from geomechanical simulations of impact events by Collins et al. (2004). The form of material flow lines are after Melosh $(1985,1989)$. The form of isotherms adapted from Ivanov and Deutsch (1999). C) Schematic "shock-deformation mechanism map" showing the relative relationship between shockdeformation microstructures in zircon with pressure, temperature, and time. Each field is labeled with the dominant process. Boundaries between fields (dashed lines) are approximate, and threshold shock pressure and temperature conditions for zircon transformation to reidite and decomposition to $\mathrm{ZrO}_{2}$ are approximate and compiled from the available literature (El Goresy 1965; Liu 1979; Ảberg and Bollmark 1985; Kusaba et al. 1985; Crocombette and Ghaleb 1998; Leroux et al. 1999; Fiske 1999). Threshold shock pressure for microtwins taken from Moser et al. (2011). Lower left hand side field is for impact-related NPFs only. Solid lines (A-D) represent hypothetical excursions experienced by zircon grains from different locations relative to an impactor shown in (A) and (B). Timeframes are adapted from schematic $T-t$ paths developed for various terrestrial impact craters (Wittmann et al. 2006). D) Schematic plot to show the approximate paths for lunar zircon of this study. i) 73235,82 zircon 1 . ii) 73235,59 zircon 3 and 76295,91 zircon 2. iii) 73215,122 zircon 5 and 72215,195 zircon 1. iv) rim of 73235,59 zircon 3. v) 73235,60 zircon 5.

both thermally activated processes that do not require stress.

Dislocation-related crystal plasticity (creep) in silicate minerals other than zircon is facilitated by high temperature and high differential stress conditions (Ashby 1972; Frost and Ashby 1982; Knipe 1989). Reddy et al. (2006) provide evidence that zircon can undergo dislocation creep as temperatures as low as amphibolites faces conditions at "tectonic" strain rates associated with ductile shear zones. However, the lower temperature limits for plasticity in zircon have not been constrained. Nevertheless, we speculate that dislocation formation and migration would not be favored at extremely high strain rates, and can occur over "plate tectonic" time scales, i.e., several million years. Moser et al. (2009, 2011) considered the thermal pulse associated with the Vredefort impact to demonstrate that dislocation creep (and associated $\mathrm{Pb}$-loss) in zircon can occur in the lower crust beyond the limits of thermal impact perturbation. This finding significantly broadens the potential provenance and preservation of impactrelated microstructures to rocks at depth in the vicinity of crater rebound.

Although there is a broad agreement on conditions for the development of shock microstructures in zircon from the available literature, the exact position and form of the fields are approximate due to sparse constraints (Fig. 15C). The various loops drawn through the deformation mechanism map represent hypothetic excursions in temperature-pressure-time space experienced 
by zircon grains from different locations relative to an impactor during an impact event (Fig. 15). Key implications from the diagrams are that they illustrate that a single zircon grain can potentially form many different impact-related microstructures during a single impact event, with a predictable relative timing sequence. The diagrams indicate that impact events tend to result in the conditions that favor dislocation creep being reached after most other microstructures have formed, with static annealing being the last process to occur. This is supported by the data where multiple microstructures are preserved. However, the complexity of the finite microstructure depends on the nature of the excursion through the deformation mechanism map (Fig. 15). Only in very large impact structures, such as Sudbury, Vredefort, and many lunar craters, will temperatures above $1500{ }^{\circ} \mathrm{C}$ prevail for a long time (Ivanov and Deutsch 1999). The data from 76295,91 zircon 2 preserve variable crystallographic misorientation across PDFs, which is interpreted to have formed by dislocation creep where dislocation glide is impeded by prior-formed PDFs, effectively compartmentalizing the grain (Fig. 10). This sequence of microstructures is consistent with formation during a single impact event (Fig. 15). 73235,59 zircon 3 shows a similar but more subtle relationship between dislocation creep and PDFs, and late annealing of twins and PDFs at the grain edge and along fractures (Figs. 8 and 9). The recrystallized domains in 73235,59 zircon 3 are overprinted by PDFs/microtwins, dislocation creep, and annealing microstructures, and therefore formed in a prior heating event (Fig. 15D). This early heating event could have been an igneous event, or a thermal event due to a far field lunar impact. Other grains presented preserve relatively simple microstructures that reflect either simple temperature-pressure loops and/or insufficient residence time in other fields (Fig. 15D). The benefits of a shockdeformation mechanism map, as shown by this study, are that it predicts that zircon from different positions relative to a single impact event will record different microstructures, and it enables multiple events to be identified from relative overprinting sequences of microstructures (e.g., Moser et al. 2011). Further research to constrain the absolute conditions for the formation of impact-related microstructures in zircon will lead to the refinement of the preliminary shock-deformation mechanism map for zircon presented in this study.

\section{CONCLUSIONS}

1. A combination of optical microscopy, SE, BSE and CL imaging, and EBSD analysis permit characterization of a wide range of impact-related microstructures in lunar zircon, including NPFs and PFs, PDFs, microtwins, and dislocation creep microstructures, and recrystallization, amorphization, and annealing microstructures.

2. PDFs and microtwins are reported here in lunar zircon for the first time, and their geometry is explained in terms of the anisotropy of elasticity of zircon and stresses associated with impact shock waves. PDF planes in zircon form normal to directions of high Young's modulus and are predominantly planes of longitudinal damage. $\{112\}$ contains directions of high shear modulus and can form twinned PDFs. $\{100\}$ contains the maxima in shear modulus but are unlikely to form PDFs at low shock pressures due to low plane-normal Young's modulus. Reidite, formed by transformation of zircon by shear along $\{100\}$ at high shock pressures, has still not been observed in lunar samples.

3. Dislocation creep microstructures are relatively common in lunar zircon, are associated with impacts, and are dominated by $<100>\{010\}$ dislocation creep system geometry.

4. Schematic deformation mechanisms maps indicate that the formation of different impact-related microstructures in zircon and their relative overprinting relationships. They predict that earlyformed shock microstructures are overprinted by ductile creep and annealing microstructures.

Acknowledgments - We thank NASA for use of the samples, and the Apollo 17 astronauts for their fieldwork. N. E. T. and S. M. R. acknowledge ARC Discovery Project DP0664078, A. A. N. and M. L. G. acknowledge ARC Discovery Project DP120102457, and N. E. T. and M. L. G. acknowledge a Curtin Internal Research Grant. S. M. R. acknowledges a Curtin University Targeted Research Fellowship. Aaron Cavosie and Des Moser are thanked for their constructive reviews of this article. We thank Falko Langenhorst for discussions on the topic. We acknowledge Alex Deutsch for editorial handling.

\section{Editorial Handling - Dr. Alexander Deutsch}

\section{REFERENCES}

Åberg G. and Bollmark B. 1985. Retention of $\mathrm{U}$ and $\mathrm{Pb}$ in zircons from shocked granite in the Siljan impact structure, Sweden. Earth and Planetary Science Letters 74:347-349.

Ashby M. F. 1972. A first report on deformation-mechanism maps. Acta Metallurgica 20:887-897.

Austrheim H. and Corfu F. 2009. Formation of planar deformation features (PDFs) in zircon during coseismic 
faulting and an evaluation of potential effects on $\mathrm{U}-\mathrm{Pb}$ systematics. Chemical Geology 261:25-31.

Bohor B. F., Betterton W. J., and Krogh T. E. 1993. Impactshocked zircons: Discovery of shock-induced textures reflecting increasing degrees of shock metamorphism. Earth and Planetary Science Letters 119:419-424.

Cavosie A. J., Quintero R. R., Radovan H. A., and Moser D. E. 2010. A record of ancient cataclysm in modern sand: Shock microstructures in detrital minerals from the Vaal River, Vredefort Dome, South Africa. Geological Society of America Bulletin 122:1968-1980.

Collins G. S., Melosh H. J., and Ivanov B. A. 2004. Modeling damage and deformation in impact simulations. Meteoritics \& Planetary Science 39:217-231.

Crocombette J.-P. and Ghaleb D. 1998. Modeling the structure of zircon: Empirical potentials, ab initio electronic structure. Journal of Nuclear Materials 257:282-286.

Deutsch A. and Schärer U. 1990. Isotope systematics and shock-wave metamorphism: I. U-Pb in zircon, titanite and monazite, shocked experimentally up to $59 \mathrm{GPa}$. Geochimica et Cosmochimica Acta 54:3427-3434.

Deutsch A. and Schärer U. 1994. Dating terrestrial impact events. Meteoritics 29:301-322.

El Goresy A. 1965. Baddeleyite and its significance in impact glasses. Journal of Geophysical Research 70:3453-3456.

Fiske P. S. 1999. Shock-induced phase transitions of $\mathrm{ZrSiO}_{4}$, reversion kinetics, and implications for impact heating in terrestrial craters. In American Physical Society, Conference on Shock Compression of Condensed Matter, June 28-July 2, 1999 (abstract \#R5.01). Snowbird, Utah: American Physical Society.

French B. M. 1969. Distribution of shock-metamorphic features in the Sudbury Basin, Ontario, Canada. Meteoritics 4:173-174.

Frost H. J. and Ashby M. F. 1982. Deformation-mechanism maps: The plasticity and creep of metals and ceramics. Oxford: Pergamon Press.

Fukunaga O. and Yamoaka S. 1979. Phase transformations in $\mathrm{ABO}_{4}$ type compounds under high pressure. Physics and Chemistry of Minerals 5:167-177.

Glass B. P. and Liu S. 2001. Discovery of high-pressure $\mathrm{ZrSiO}_{4}$ polymorph in naturally occurring shock-metamorphosed zircons. Geology 29:371-373.

Grange M. L., Nemchin A. A., Pidgeon R. T., Timms N., Muhling J. R., and Kennedy A. K. 2009. Thermal history recorded by the Apollo 17 impact melt breccia 73217 . Geochimica et Cosmochimica Acta 73:3093-3107.

Grange M. L., Nemchin A. A., Timms N., Pidgeon R. T., and Meyer C. 2011. Complex 1 magmatic and impact history prior to $4.1 \mathrm{Ga}$ recorded in zircon from Apollo 17 South Massif aphanitic breccia 73235. Geochimica et Cosmochimica Acta 75:2213-2232.

Grieve R. A. F. and Robertson P. B. 1976. Variations in shock deformation at the Slate Islands impact structure, Lake Superior, Canada. Contributions to Mineralogy and Petrology 58:37-49.

Grieve R. A. F., Langenhorst F., and Stoeffler D. 1996. Shock metamorphism of quartz in nature and experiment; II, Significance in geoscience. Meteoritics 31:6-35.

Gucsik A., Zhang M., Koeberl C., Salje E. K. H., Redfern S. A. T., and Pruneda J. M. 2004. Infrared and Raman spectra of $\mathrm{ZrSiO}_{4}$ experimentally shocked at high pressures. Mineralogical Magazine 68:801-811.
Hazen R. M. and Finger L. W. 1979. Crystal structure and compressibility of zircon at high pressure. American Mineralogist 64:196-201.

Hearmon R. F. S. 1984. The elastic constants of crystals and other anisotropic materials. In Landolt-Börnstein Tables III, vol. 18, edited by Hellwege K. H. and Hellwege A. M. New York: Springer-Verlag. pp. 1-140.

Humphreys F. J. and Hatherly M. 1996. Recrystallization and related annealing phenomena. Oxford: Pergamon.

Ivanov B. A. and Deutsch A. 1999. Sudbury impact event: Cratering mechanics and thermal history. In Large meteorite impacts and planetary evolution II, edited by Dessler B. and Grieve R. A. F. Special Paper 339. Washington, D.C.: Geological Society of America. pp. 389-397.

James O. B., Brecher A., Blanchard D. P., Jacobs J. W., Brannon J. C., Korotev R. L., Haskin L. A., Higuchi H., Morgan J. W., Anders E., Silver L. T., Marti K., Braddy D., Hutcheon I. D., Kirsten T., Kerridge J. F., Kaplan I. R., Pillinger C. T., and Gardiner L. R. 1975. Consortium studies of matrix of light gray breccia 73215. Proceedings, 6th Lunar Science Conference. pp. 547-577.

Jourdan F., Renne P. R., and Reimold W. U. 2009. An appraisal of the ages of terrestrial impact structures. Earth and Planetary Science Letters 286:1-13.

Kaczmarek M. A., Reddy S. M., and Timms N. E. 2011. Evolution of zircon deformation mechanisms in a shear zone (Lanzo massif, Western-Alps). Lithos 127(3-4):414 426.

Kamo S. L., Reimold W. U., Krogh T. E., and Colliston W. P. 1996. A $2.023 \mathrm{Ga}$ age for the Vredefort impact event and a first report of shock metamorphosed zircons in pseudotachylitic breccias and granophyre. Earth and Planetary Science Letters 144:369-387.

Kelley S. P. and Sherlock S. C. Forthcoming. The geochronology of impact craters. In Impact cratering: Processes and products, edited by Osinski G. R. and Peierazzo E. Milton Keynes: Open University.

Kleinmann B. 1969. The breakdown of zircon observed in the Libyan desert glass as evidence of its impact origin. Earth and Planetary Science Letters 5:497-501.

Knipe R. J. 1989. Deformation mechanisms-recognition from natural tectonites. Journal of Structural Geology 11:127-146.

Krogh T. E., Davis D. W., and Corfu F. 1984. Precise U-Pb zircon and baddeleyite ages for the Sudbury area. In The geology and ore deposits of the sudbury structure, vol. 1, edited by Pye E. G., Naldret A. J., and Giblin P. E. Toronto: Ontario Geological Survey Special Publication. pp. 431-446.

Krogh T. E., Kamo S. L., Sharpton V. L., Marin L. E., and Hildebrands A. R. 1993. U-Pb ages of single shocked zircons linking distal $\mathrm{K} / \mathrm{T}$ ejecta to the Chicxulub crater. Nature 366:731-734.

Kusaba K., Syono Y., Kikuchi M., and Fukuoka K. 1985. Shock behavior of zircon: Phase transition to scheelite structure and decomposition. Earth and Planetary Science Letters 72:433-439.

Kusaba K., Yagi T., Kikuchi M., and Syono Y. 1986. Structural considerations on the mechanism of the shockinduced zircon-scheelite transition in $\mathrm{ZrSiO}_{4}$. Journal of Physics and Chemistry of Solids 47:675-679.

Langenhorst F. 2002. Shock metamorphism of some minerals: Basic introduction and microstructural observations. Bulletin of the Czech Geological Survey 77:265-282. 
Langenhorst F. and Deutsch A. 1994. Shock experiments on pre-heated $\alpha$ - and $\beta$-quartz: I. Optical and density data. Earth and Planetary Science Letters 125:407-420.

Leroux H., Reimold W. U., Koeberl C., Hornemann U., and Doukhan J. C. 1999. Experimental shock deformation in zircon: A transmission electron microscopic study. Earth and Planetary Science Letters 169:291-301.

Liu L. G. 1979. High-pressure phase transformations in baddeleyite and zircon, with geophysical implications. Earth and Planetary Science Letters 44:390-396.

Liu D., Wan Y., Zhang Y., Dong C., Jolliff B. L., Zeigler R. A., and Korotev R. L. 2009. Age of the zircons in the impact-melt breccia in SaU 169 lunar meteorite: Beijing SHRIMP II study (abstract \#2499). 40th Lunar and Planetary Science Conference. CD-ROM.

Liu D., Jolliff B. L., Zeigler R. A., Wan Y., Zhang Y., Dong C., and Korotev R. L. 2010. A 3.91 billion year age for Apollo 12 high-thorium impact melt breccias: Products of Imbrium, or an older impact basin in the Procellarum KREEP Terrane? (abstract \#2477). 41st Lunar and Planetary Science Conference. CD-ROM.

Marvin U. B. 1975. The boulder. Earth, Moon, and Planets 14:315-326.

Melosh H. J. 1985. Impact cratering mechanics: Relationship between the shock wave and excavation flow. Icarus 62:339-343.

Melosh H. J. 1989. Impact cratering: A geologic process. New York: Oxford University Press. 245 p.

Meyer C. 1994. Catalogue of Apollo 17 Rocks Volume 4 North Massif - LPI Office of the Curator \#87. JSC \#26088. Houston, Texas: Lunar and Planetary Institute. 644 p.

Meyer C., Williams I. S., and Compston W. 1996. Uraniumlead ages for lunar zircons; evidence for a prolonged period of granophyre formation from 4.32 to $3.88 \mathrm{Ga}$. Meteoritics 31:370-387.

Moser D. E., Davis W. J., Reddy S. M., Flemming R. L., and Hart R. J. 2009. Zircon U-Pb strain chronometry reveals deep impact-triggered flow. Earth and Planetary Science Letters 277:73-79.

Moser D. E., Cupelli C. L., Barker I. R., Flowers R. M., Bowman J. R., Wooden J., and Hart J. R. 2011. New zircon shock phenomena and their use for dating and reconstruction of large impact structures revealed by electron nanobeam (EBSD, CL, EDS) and isotopic $\mathrm{U}-\mathrm{Pb}$ and (U-Th)/he analysis of the Vredefort dome. Canadian Journal of Earth Sciences 48:117-139.

Nemchin A., Timms N. E., Pidgeon R., Geisler T., Reddy S. M., and Meyer C. 2009. Timing of crystallization of the lunar magma ocean constrained by the oldest zircon. Nature Geoscience 2:133-136.

Pidgeon R. T., Nemchin A. A., van Bronswijk W., Geisler T., Meyer C., Compston W., and Williams I. S. 2007. Complex history of a zircon aggregate from lunar breccia 73235 . Geochimica et Cosmochimica Acta 71:1370-1381.

Pidgeon R., Nemchin A., and Kamo S. L. 2011. Comparison of structures in zircons from lunar and terrestrial impactites. Canadian Journal of Earth Sciences 48:107-116.

Putnis A. 2002. Mineral replacement reactions: From macroscopic observations to microscopic mechanisms. Mineralogical Magazine 66:689-708.

Reddy S. M., Timms N. E., Trimby P., Kinny P. D., Buchan C., and Blake K. 2006. Crystal-plastic deformation of zircon: A defect in the assumption of chemical robustness. Geology 34:257-260.
Reddy S. M., Timms N. E., Pantleon W., and Trimby T. 2007. Quantitative characterization of plastic deformation of zircon and geological implications. Contributions to Mineralogy and Petrology 153:625-645.

Reddy S. M., Timms N. E., and Eglington B. M. 2008. Electron backscatter diffraction analysis of zircon: A systematic assessment of match unit characteristics and pattern indexing optimization. American Mineralogist 93:187-197.

Reddy S. M., Timms N. E., Hamilton P. J., and Smyth H. R. 2009. Deformation-related microstructures in magmatic zircon and implications for diffusion. Contributions to Mineralogy and Petrology 157:231-244.

Reid A. F. and Ringwood A. E. 1969. Newly observed high pressure transformations in $\mathrm{Mn}_{3} \mathrm{O}_{4}, \mathrm{CaAl}_{2} \mathrm{O}_{4}$, and $\mathrm{ZrSiO}_{4}$. Earth and Planetary Science Letters 6:205-208.

Reimold W. U., Leroux H., and Gibson R. L. 2002. Shocked and thermally metamorphosed zircon from the Vredefort impact structure, South Africa: A transmission electron microscopic study. European Journal of Mineralogy 14:859868.

Robertson P. B. and Grieve R. A. F. 1977. Shock attenuation at terrestrial impact structures. In Impact and explosion cratering: Planetary and terrestrial implications; Proceedings of the Symposium on Planetary Cratering Mechanics, Flagstaff, Ariz., September 13-17, 1976, edited by Roddy D. J., Pepin R. O., and Merrill R. B. New York: Pergamon Press, Inc. pp. 687-702.

Ryder G. 1993. Catalog of Apollo 17 rocks, Volume 1-Stations 2 and 3 (South Massif). LPI Office of Curator \#87. JSC \#26088. Houston, Texas: Lunar and Planetary Institute.

Ryder G., Stoeser D. B., Marvin U. B., Bower J. F., and Wood J. A. 1975. Boulder 1, Station 2, Apollo 17: Petrology and petrogenesis. Earth, Moon, and Planets 14:327-357.

Schärer U. and Deutsch A. 1990. Isotope systematics and shock-wave metamorphism: II. U-Pb and $\mathrm{Rb}-\mathrm{Sr}$ in naturally shocked rocks; the Haughton Impact Structure, Canada. Geochimica et Cosmochimica Acta 54:3435-3447.

Spudis P. D. and Ryder G. 1981. Apollo 17 impact melts and their relation to the Serenitatis basin. In Multi-ring basins: Formation and evolution. Proceedings, 12th Lunar and Planetary Science Conference. pp. 133-148.

Stöffler D. and Langenhorst F. 1994. Shock metamorphism of quartz in nature and experiment; I, Basic observation and theory. Meteoritics 29:155-181.

Stöffler D. and Ryder G. 2001. Stratigraphy and isotope ages of lunar geologic units: Chronological standard for the inner solar system. Space Science Reviews 96:9-54.

Stubican V.-S. and Roy R. 1963. High-pressure scheelitestructure polymorphs of rare-earth vanadites and arsenites. Zeitschrift für Kristallographie 119:90-97.

Taylor S. R. and Ewing R. C. 1978. The crystal structure of the $\mathrm{ThSiO}_{4}$ polymorphs: Huttonite and thorite. Acta Crystallographica, Section B: Structural Science 34:10741079 .

Timms N. E. and Reddy S. M. 2009. Response of cathodoluminescence to crystal-plastic deformation in zircon. Chemical Geology 261:11-23.

Timms N., Kinny P., and Reddy S. 2006. Enhanced diffusion of uranium and thorium linked to crystal plasticity in zircon. Geochemical Transactions 7:10.

Timms N. E., Healy D., Reyes-Montes J. M., Collins D. S., Prior D. J., and Young R. P. 2010. Effects of 
crystallographic anisotropy on fracture development and acoustic emission in quartz. Journal of Geophysical Research 115:B07202.

Timms N. E., Kinny P. D., Reddy S. M., Evans K., Clark C., and Healy D. 2011. Relationship among titanium, rare earth elements, U-Pb ages and deformation microstructures in zircon: Implications for Ti-in-zircon thermometry. Chemical Geology 280:33-46.

Timms N. E., Reddy S. M., Fitz Gerald J. D., Green L., and Muhling J. R. Forthcoming. Inclusion-localised crystalplasticity, dynamic porosity, and fast-diffusion pathway generation in zircon. Journal of Structural Geology, doi:10.1016/j.jsg.2011.11.005.
Turley J. and Sines G. 1971. The anisotropy of Young's modulus, shear modulus and Poisson's ratio in cubic materials. Journal of Physics D: Applied Physics 4:264-271.

Wilkinson A. J. 2000. Measuring strains using electron backscatter diffraction. In Electron backscatter diffraction in materials science, edited by Schwartz A. J., Kumar M., and Adams B. L. New York: Kluwer Academic/Plenum. pp. 231-246.

Wittmann A., Kenkmann T., Schmitt R. T., and Stöffler D. 2006. Shock-metamorphosed zircon in terrestrial impact craters. Meteoritics \& Planetary Science 41:433-454.

Wood J. A. 1975. The nature and origin of Boulder 1, Station 2, Apollo 17. Earth, Moon, and Planets 14:505-517. 